This item was submitted to Loughborough's Research Repository by the author.

Items in Figshare are protected by copyright, with all rights reserved, unless otherwise indicated.

\title{
A methodological framework for crafting situated services
}

\section{PLEASE CITE THE PUBLISHED VERSION}

https://doi.org/10.1108/JOSM-05-2020-0188

\section{PUBLISHER}

Emerald

VERSION

AM (Accepted Manuscript)

\section{PUBLISHER STATEMENT}

This paper was accepted for publication in the journal Journal of Service Management and the definitive published version is available at https://doi.org/10.1108/JOSM-05-2020-0188

\section{LICENCE}

CC BY-NC 4.0

\section{REPOSITORY RECORD}

Mazzarella, Francesco, Andrew May, and Val Mitchell. 2021. "A Methodological Framework for Crafting Situated Services". Loughborough University. https://hdl.handle.net/2134/15172890.v1. 


\title{
A Methodological Framework for Crafting Situated Services
}

\author{
Abstract \\ Purpose: This paper discusses how service design can be used to activate a transition of textile \\ artisan communities towards a sustainable future. Design/methodology/approach: Two \\ participatory case studies were undertaken with textile artisans in the UK and South Africa. These \\ led to the development of an original methodological framework for 'crafting situated services' - \\ services designed to be meaningful to the local communities within which they are embedded. \\ An evaluation study assessed the originality of the framework, its relevance for tackling real- \\ world problems, its extensibility and the rigour of the research process. Findings: The framework \\ brings together a variety of roles, methods and tools that designers can adopt in order to enter \\ communities, make sense of sustainable futures, facilitate the co-design of situated services, and \\ activate legacies within communities. Building on emerging anthropological approaches, the \\ framework makes a bridge between service management and service design for social innovation, \\ advancing the field towards design for social entrepreneurship. Originality/value: Arguing against \\ the idea of the designer 'parachuting' into communities to create services regardless of the local \\ context, the concept of 'situated services' is proposed in this paper, alongside a process for \\ 'crafting' meaningful social innovations. This requires the service designer to adopt a more \\ situated and embedded approach to designing with communities in order to align with their \\ needs and aspirations, interweave places, time, people and practices within the process, and co- \\ design contextually better services.
}

Keywords: service design, social innovation, sustainable futures, design anthropology, textile artisan communities.

\section{Introduction}

The current system of artisanal production is unsustainable with respect to autonomous livelihoods, social equality, cultural heritage, and environmental stewardship (Scrase, 2003). To alleviate these problems and trigger innovation, a range of 'top-down' strategies has been deployed by governments and non-governmental organisations, but these are often ineffective in addressing the specific needs and aspirations of diverse local communities; consequently, the proposed new ideas are not adopted by the artisans. On the other hand, 'bottom-up' initiatives activated by communities also face organizational and resource constraints that prevent them from being sustainable in the long-term. Within this context, service design has become a wellestablished human-centred, strategic and systemic approach to tackling such challenges and contributing to social innovation and sustainability (Meroni and Sangiorgi, 2011). Although only 'modest attention' has been given to service design and innovation (Patrício et al., 2018), 
Anderson et al., (2018) state how "service design is ideally suited to help achieve transformative service research's goals because design is oriented to action".

Design thinking and associated practices can be used as a key means for collaborative and crossdisciplinary service innovation (Yu and Sangiorgi, 2018). However, service designers have put much emphasis on the use of fixed toolkits that result in 'one-size-fits-all' outputs (Akama and Prendiville, 2013; Sangiorgi and Prendiville, 2017). Instead, there is a need for a more situated and embedded approach to service design (Sangiorgi and Junginger, 2015). This paper reports on a research project which explored new roles, purposes and methods that the service designer can adopt to activate communities to transition towards a sustainable future (Mazzarella, 2018). Building on emerging anthropological approaches to service design (Blomberg and Darrah, 2015), this paper presents and evaluates an original methodological framework which, when embodied with appropriate methods and tools, equips the service designer with cultural sensitivity when entering communities, making sense of sustainable futures, facilitating the co-design of situated services, and activating legacies within communities. In this paper, the diverse roles - as a cultural insider, storyteller, sensemaker, facilitator, and activist - that the service designer can play throughout a social innovation journey are discussed. To conclude, the paper emphasises that the mastery of the designer lies in the skill of tailoring his/her approach to specific contexts in order to craft situated services that are meaningful to the communities using them.

\section{Literature Review}

To overcome the sustainability challenges and 'wicked problems' (Kolko, 2012) of the present and future world, designers are increasingly adopting a more ethical approach and embedding social responsibility in their work (Manzini, 2015), whilst playing an activist role (Fuad-Luke, 2009; Fuad-Luke et al., 2015), which is crucial to catalysing social innovations. Social innovations are defined as "new solutions (ideas, products, services, models, markets, processes, etc.) that simultaneously meet a social need (more effectively than existing solutions) and lead to new or improved capabilities and relationships, and to a better use of assets and resources"(The Young Foundation, 2012, p. 18). Social innovations may initiate from within communities, but expert designers are also intervening to make things happen (Manzini, 2014). For instance, designers are collaborating with artisans in order to gain pleasure by making things by hand (Sennet, 2008), strengthen community connections (Thomas et al., 2011) and re-localise production (Micelli, 2011). Within this context, designers activate local initiatives which empower communities to be directly involved in the problems they are affected by instead of seeking a single, large, complex and unitary 'top-down' solution (Green, 2013). 'Top-down' approaches have often been ineffective in addressing the diverse needs of local communities (Boivard, 2007); therefore, designers are increasingly playing a crucial role in co-creating services, strategies and systems that enable 'bottom-up' social innovations to flourish, be sustained and scaled up through the synergy with and support of 'top-down' organisations. On the other hand, although designers are broadening their skill-set to address social issues, they are often Western or Western-trained professionals, driven by their individual passion to 'do good' or by the agenda of aid organisations, intervening in (usually non-Western) disadvantaged communities. The need to explicitly tackle issues of exclusion within service design is highlighted by Fisk et al., (2018). It is increasingly 
recognised that simple interventions within disadvantaged groups can bring with themselves the limitation of jumping too quickly into technical fixes before a deep dive into the root causes behind the symptoms of the problem is undertaken (Willis and Ebana, 2017). To counter the practice of 'parachuting' into projects that do not subsequently flourish, the designer should instead draw on the situated knowledge of multi-disciplinary stakeholders and co-operate towards a social aim (Parker and Parker, 2007; Needham, 2008).

\subsection{An Anthropological Approach to Service Design}

Design methods have become a way to legitimize the field of service design resulting in the perception that methods can be 'commodified' for repeatability and separated from the specific design practitioner (Akama and Light, 2012). Moreover, although design thinking has become a widespread practice, its focus on problem-solving has limited its contribution to an operational and technical role. Instead, going beyond feasibility and viability concerns, the cultural dimension of design for social innovation needs to be emphasized (Meroni and Selloni, 2018). Social innovations, in order to be meaningful, need to be co-created with designers, users and stakeholders, and require a 'cultural translation' to fit the local context in which they are to be used, addressing the overlooked issue of desirability and acceptability of services. They need to be developed based on an understanding of the fundamental components of the ecosystem of interest, including norms, rules, meanings, symbols and practices (Baron et al., 2018). Akama and Prendiville (2013) argue for the need to adopt a collaborative and phenomenological approach to service design so that services are integrated in local contexts and become meaningful to peoples' lives. With this in mind, services are here defined as 'situated' when deeply rooted in a place and mindful of different notions of time, when their features are tailored to the needs of the people who use and produce them, and when local tacit knowledge and everyday practices are embedded within them. From this perspective, there is the need to understand how the service designer can be more embedded within the context of intervention and establish a more inclusive relationship with communities to develop meaningful social innovations. This aligns with, and builds on, the discussion by Joly et al., (2019) in relation to the connection between multi-disciplinary service design and service innovation.

\subsection{Designing Services with Textile Artisan Communities}

Given that service design offers the potential to activate sustainable futures, but that both 'topdown' and 'bottom-up' initiatives do not necessarily succeed, the research presented in this paper focused on textile artisanal production as a means of investigating how to design situated services. We are witnessing an increased interest in artisanship (i.e. the practice of skilled work with materials, by hand or with tools, to produce quality products grounded in the material culture of a place) as a key contributor to sustainability, cultural identity and wellbeing. However, artisans often find themselves working in an isolated and precarious condition, residing at the bottom of an ecosystem, which does not take people, the heritage and the environment into account (Mirza, 2020). Within the artisanal landscape, a great potential for social innovation and sustainable development was identified in the textile sector through holistic strategies aimed at enhancing environmental stewardship, regenerating local economies, revitalising cultural heritage, and 
nurturing social engagement. This is due to the high employment rate of skilled artisans (Crafts Council, 2014), the wide range of applications - from clothing to homeware to consumer products (Wilson, 2011) - and ever-increasing consumer demand. These create opportunities but also cause significant sustainability challenges in relation to the environment, economy, society and culture (Earley et al., 2010). Within the context of this paper, textile artisanship is defined as the humancentred economic activity of giving form and meaning to locally sourced fibres. Through skilled handwork or by directly handling mechanized or digital tools, textile artisans manage the process of making small and flexible batches of textiles and apparel. Furthermore, this paper focuses on textile artisan communities, considered as 'bottom-up' aggregations based on formal or informal synergies amongst artisans working in physical proximity and sharing a material cultural background as well as working together towards one collective goal.

\subsection{A Framework for Crafting Situated Services}

The research discussed in this paper investigated how service design can be used to activate a transition of textile artisan communities towards a sustainable future. It attempts to tackle the challenge identified by Brodie and Peters (2020), i.e. bridging the gap between theory and practice, while also ensuring that theorizing is managerially relevant. The purpose of this paper is to discuss the development and evaluation of an original methodological framework that can aid designers in co-designing situated services with textile artisan communities and activating a transition towards a sustainable future. It complements existing frameworks such as that developed by Alkire et al. (2019) by being more process-focused, and explicitly considering the different roles that a service designer can play throughout a social innovation journey, when a multidisciplinary approach is being taken. The framework proposes a process for 'crafting situated services' ensuring that they are deeply rooted in a locale before they could be replicated by others across contexts.

\section{Methodology}

The project discussed in this paper adopted case studies as an overarching research strategy to investigate a contemporary real-life phenomenon in its actual setting and gather socially and culturally rich data (Yin, 2004). Due to the emancipatory purpose of the project, the cases were studied through a participatory design approach (Simonsen and Robertson, 2013), consisting of collaboration and mutual learning between the researcher and multiple participants in order to activate meaningful social innovations. The research comprised multiple phases, as shown in Figure 1. This outlines the different objectives of the project, and the multiple methods adopted to deliver specific outcomes. This paper summarizes the findings from the earlier phases, and provides more detailed results from the final evaluation study. 


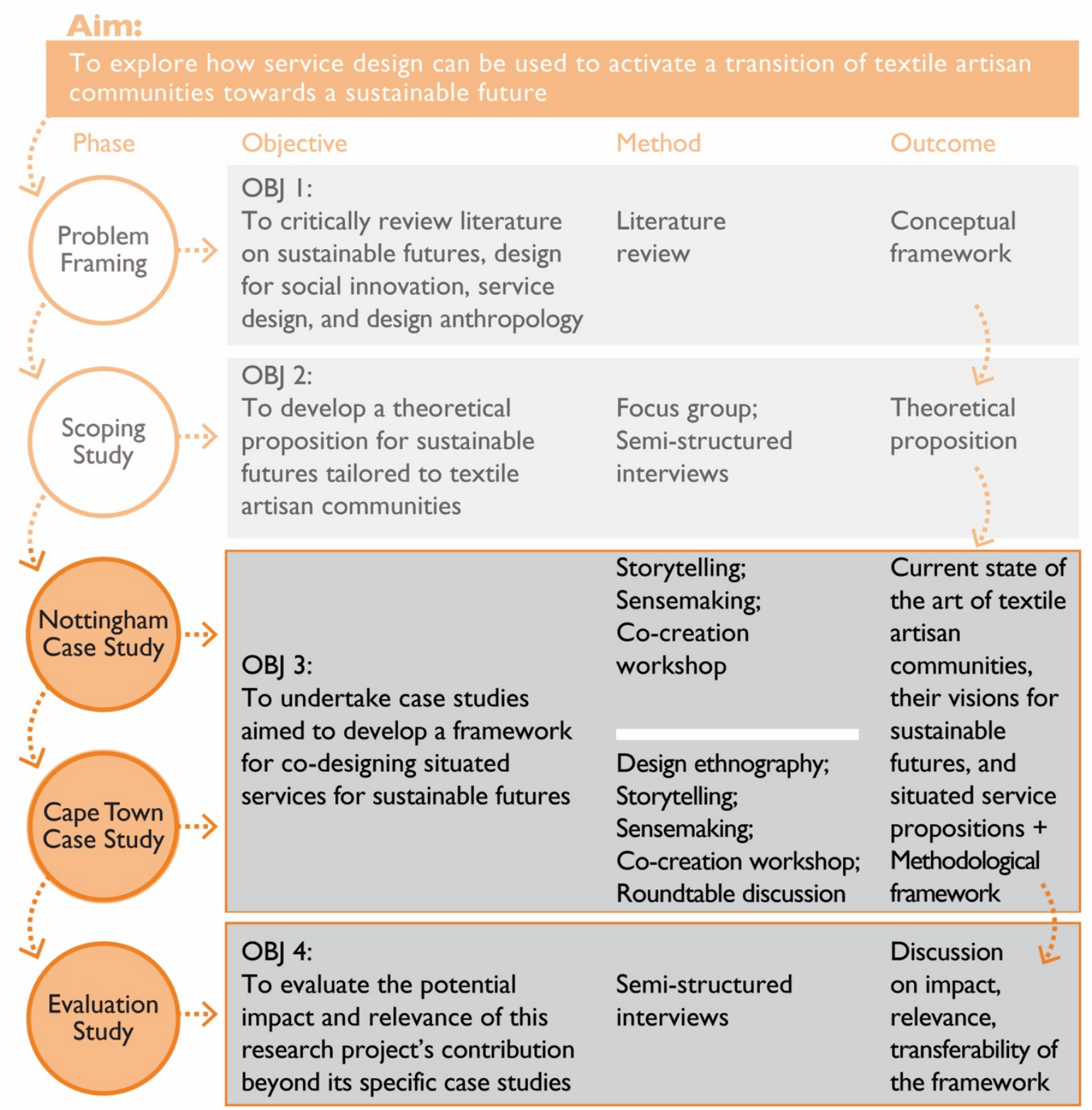

Figure 1: Research design of the project discussed in this paper.

\subsection{Initial Conceptual Framework}

Building on a literature review, an initial conceptual framework was constructed as an anthropological lens for service design for social innovation and sustainability. Aided by a scoping study with international academic experts in sustainable design, a theoretical proposition for sustainable futures was developed.

\subsection{Participatory Case Studies and Framework Development}

The initial framework was used to design two participatory case studies conducted with textile artisan communities in Nottingham, UK (Mazzarella et al., 2017) and Cape Town, South Africa (Mazzarella et al., 2018).

Nottingham has been the heart of lace design and manufacturing in the world for three centuries, and the legacy of this commercial textile tradition can still be seen within its built environment, especially in the Lace Market area of the city (Mason, 2010; Briggs-Goode and Dean, 2013). The 
sector has been seriously endangered by overseas competition, causing the closure of most of the factories and the disappearance of heritage know-how among current generations (Fisher et al., 2016). An opportunity was recognised for encouraging the artisans to join together as a collaborative cluster to revitalise the lace heritage and contribute to Nottingham's sustainable development.

Cape Town was chosen as an exemplary context for co-designing social innovations with communities. In fact, the concept of 'ubuntu' (meaning 'humanity towards others'), as a traditional form of self-reliance and mutual support, broadly inspires the South African way of thinking and doing (Rhodes, 2015). However, the textile cluster in Cape Town is challenged by deep social inequalities, cultural appropriation issues, market competition, and manufacturing challenges (Morris and Reed, 2008). On the other hand, this issue has become a driver for local artisans to start up new businesses focused on printing on available base cloth to differentiate their products over competition (Miller, 2017).

In both studies, multiple methods (i.e. design ethnography, storytelling, sensemaking, co-creation workshops, and roundtable discussions) were adopted to collect qualitative data, which was thematically analysed to gather insights about the co-design of situated service propositions with communities and to understand the implications of adopting an anthropological approach to service design. A summary of results from these case studies is provided in Section 4. Adopting an abductive approach (Dubois and Gadde, 2002), the theoretical findings from the literature review and the empirical results of the case studies were integrated into the development of an original methodological framework for 'crafting situated services', which is described in detail in Section 5.

\subsection{Framework Validation}

The methodological framework informed by the literature review and developed through the case studies was validated through an evaluation study, the results of which comprise the main data for this paper. Semi-structured interviews were conducted with questions tailored to the diverse range of expertise of the respondents (Kvale, 1996). The participants in the evaluation study were six experts in service design for social innovation (Table I), as a mix of academics, practitioners and members of organisations working with communities both in the Global North and in the Global South, specifically chosen to give varied and complementary views regarding the efficacy of the framework.

Table I. Sample panel of the evaluation study.

\begin{tabular}{ll} 
Name & Expertise \\
\hline Participant 1 & $\begin{array}{l}\text { Professor in service design for social innovation, with expertise in the } \\
\text { sociocultural qualities of services designed with grassroots communities in } \\
\text { the Global South. }\end{array}$ \\
\hline Participant 2 & $\begin{array}{l}\text { Design practitioner with over ten years of experience in adopting service } \\
\text { design thinking with grassroots communities to design meaningful social } \\
\text { innovations in the Global South. }\end{array}$ \\
\end{tabular}




\begin{tabular}{ll}
\hline Participant 3 & $\begin{array}{l}\text { Service design practitioner, with over ten years of experience in activism and } \\
\text { co-creation with communities and public administrations in the Global } \\
\text { North. }\end{array}$ \\
\hline Participant 4 & $\begin{array}{l}\text { Project manager with experience in embedding service design in a third } \\
\text { sector organization to design social innovations, and with research expertise } \\
\text { in design as future-making, working in the Global North. }\end{array}$ \\
\hline Participant 5 & $\begin{array}{l}\text { Cultural anthropologist, with ten years of experience in consulting } \\
\text { organisations to design services for social innovations with grassroots } \\
\\
\text { communities in the Global South. }\end{array}$ \\
\hline Participant 6 & $\begin{array}{l}\text { Professor in service design, with expertise in empowering communities to } \\
\text { design meaningful social innovations, working in the Global North. }\end{array}$ \\
\hline
\end{tabular}

The interviews began with an introductory presentation about the whole research project. The interviewees were then asked to evaluate the potential application of the framework in relation to a service design (research) project of their own aimed at activating social innovations with communities. The interviewees answered four questions about the invention, relevance, and extensibility of the framework, and the rigour of the research process. The interviews were conducted via Skype, and lasted approximately one hour each.

The interviews were audio recorded, transcribed, and thematically analysed, following a manual, iterative process that encompassed data reduction, display and conclusion drawing, as per Miles and Huberman (1994). The process of data reduction entailed selecting, synthesising, and transforming data from transcripts into summary sheets with codes and memos. Informed by the criteria for evaluating design research (i.e. invention, relevance, extensibility, process) drawn from Zimmerman et al. (2007), a priori codes were used to analyse the data, as outlined in Table II. These were then integrated with further sub-themes emerging from the data through a datadriven inductive process. Data displays in the form of tables were produced to represent coded data (with category names attributed to meaningful segments of the transcription) and facilitate the recognition and comparison of themes, identified as patterns cutting across the interviews. Finally, conclusions were drawn from the data by identifying themes and sub-themes, and outlining relationships between them.

Table II. Coding system used for the analysis of the data collected through the interviews.

\begin{tabular}{ll} 
Code & Code description \\
\hline Invention & $\begin{array}{l}\text { Novel integration of various subject matters to address a specific situation and } \\
\text { advance the current state of the art in the research community. }\end{array}$ \\
\hline Relevance & $\begin{array}{l}\text { Credibility of the research framed within the real-world, and of its findings } \\
\text { leading to address a critically-articulated research problem. }\end{array}$ \\
\hline Extensibility & $\begin{array}{l}\text { Ability to either employ the process in a future design problem, or build on the } \\
\text { resulting outcomes of the research. }\end{array}$ \\
\hline Process & Rigour applied to the research influencing the reproducibility of the process. \\
\hline
\end{tabular}




\section{Key Findings from the Case Studies}

The service design process undertaken in the first case study allowed understanding of the locale and mapping out of the current state of the art of Nottingham lace artisanship, as a complex web of small businesses, specialized in producing diverse types of lace (Figure 2).

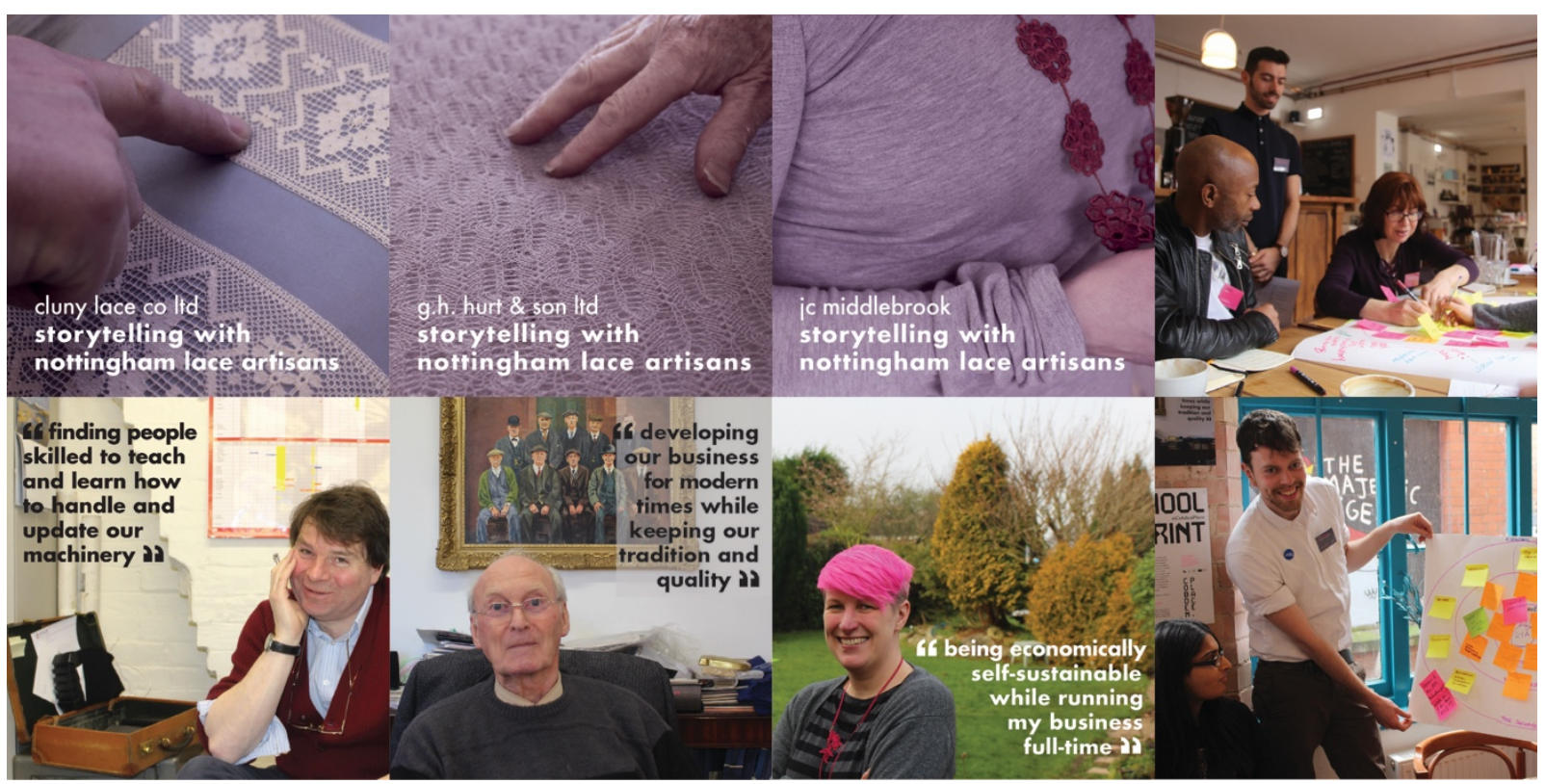

Figure 2: Snapshots from the Nottingham case study.

The study shed light on the hidden wealth of cultural heritage, social engagement initiatives and creative economy surrounding the industry, with the potential to revitalize the local heritage textiles how-how, as stated by one participant (a member of a support organisation): "It is nice to see contemporary work going on around the lace industry that we had for a long period of time in Nottingham. It is nice to see the continuation of that work, in a modern and quite exciting way. People are passionate about retaining that knowledge and bringing it forward. I hope that Nottingham is once again known for its lace artisanal making. I think that would be a terrific achievement for Nottingham".

Through sensemaking, the concept of sustainable futures was unpacked into its social, cultural and economic facets. The artisans envisioned a socio-technical innovation entailing skills transfer, the development of a contemporary aesthetic, and the flourishing of independent full-time businesses. Within this context, it emerged that some futures (e.g. circular and sharing economy) may remain a form of vision for the artisans, while others (e.g. slow consumption, and flexible production) were already present in their practices. Through co-design with a wider group of stakeholders, a design direction was framed around the challenge of making lace-inspired artisans economically sustainable in Nottingham and building a sense of place. Two strategies were outlined, i.e. a shared research agenda to identify gaps in the heritage artisanal businesses and inform education of future artisans and consumers; and a supporting strategy boosting the economic development of local businesses. The networks of stakeholders who could support the implementation of the strategies were mapped and merged into a 'middle-up-down' strategy for 
collaboration between 'bottom-up' initiatives and 'top-down' support. A service proposition was outlined, i.e. a 'co-designer in residence' service enabling bespoke and situated engagement between contemporary designers and heritage artisans, with the aim of innovating the lacemaking businesses. Finally, a manifesto was co-designed outlining the core values anchoring the stakeholders together as a community, grounded in trust, co-creation, quality, provenance, sustainability, modernity, awareness, and pride.

The Nottingham Case Study also led to the identification of key issues to be considered when codesigning situated services for social innovation. The case study highlighted the need for building an authentic narrative to raise people's awareness, enabling local stakeholders to share a meaningful vision for sustainable futures, and framing a future strategy to encourage collaboration towards place-making. Building a 'middle-up-down' network of stakeholders was recommended as a way to support the co-design of a situated service proposition, embedding values shared amongst the community in order to encourage its resilience. In this regard, one participant (member of a support organisation) stated: "The system is going to support the lace artisans to be more sustainable. What we really need then is to have the lace-inspired artisans at the centre, because the service is all focused on them. So, at the core there are artisans making and selling stuff, otherwise the service is meaningless".

Self-reflection throughout the process undertaken helped identify the limitations of the Nottingham case study and outline recommendations for the subsequent case study. In Cape Town, the methods were reviewed and further developed. An initial scoping activity (built on methods drawn from ethnography) was introduced to discover the context around textile artisans, and tailor the intervention to local dynamics. In the Cape Town case study, interview cards were designed to aid the researcher in conducting the storytelling sessions in the artisans' workspaces in a fluid, yet comprehensive way. In the Nottingham case study, the need to separate the keywords from the 'ideas generation' template into cards emerged in order to better allow the artisans to envision sustainable futures, without feeling overwhelmed by future issues they did not fully understand. The participants' feedback also highlighted a shortage of lace artisans in the co-creation workshop in Nottingham (over a majority of support organisation members).

Therefore, in the Cape Town case study, the designer conducted the co-creation workshop only with artisans, in order to allow them to generate 'bottom-up' solutions, avoiding the risk of 'topdown' support organisations leading the process. The involvement of multiple perspectives was postponed to a later stage, at a roundtable discussion which was introduced at the end to activate a legacy within the local community and build a wider network of stakeholders to support the implementation of the designed service.

In order to overcome the limitations of the Nottingham case study and assess the transferability of the framework, a second participatory case study was conducted in Cape Town (Figure 3). 


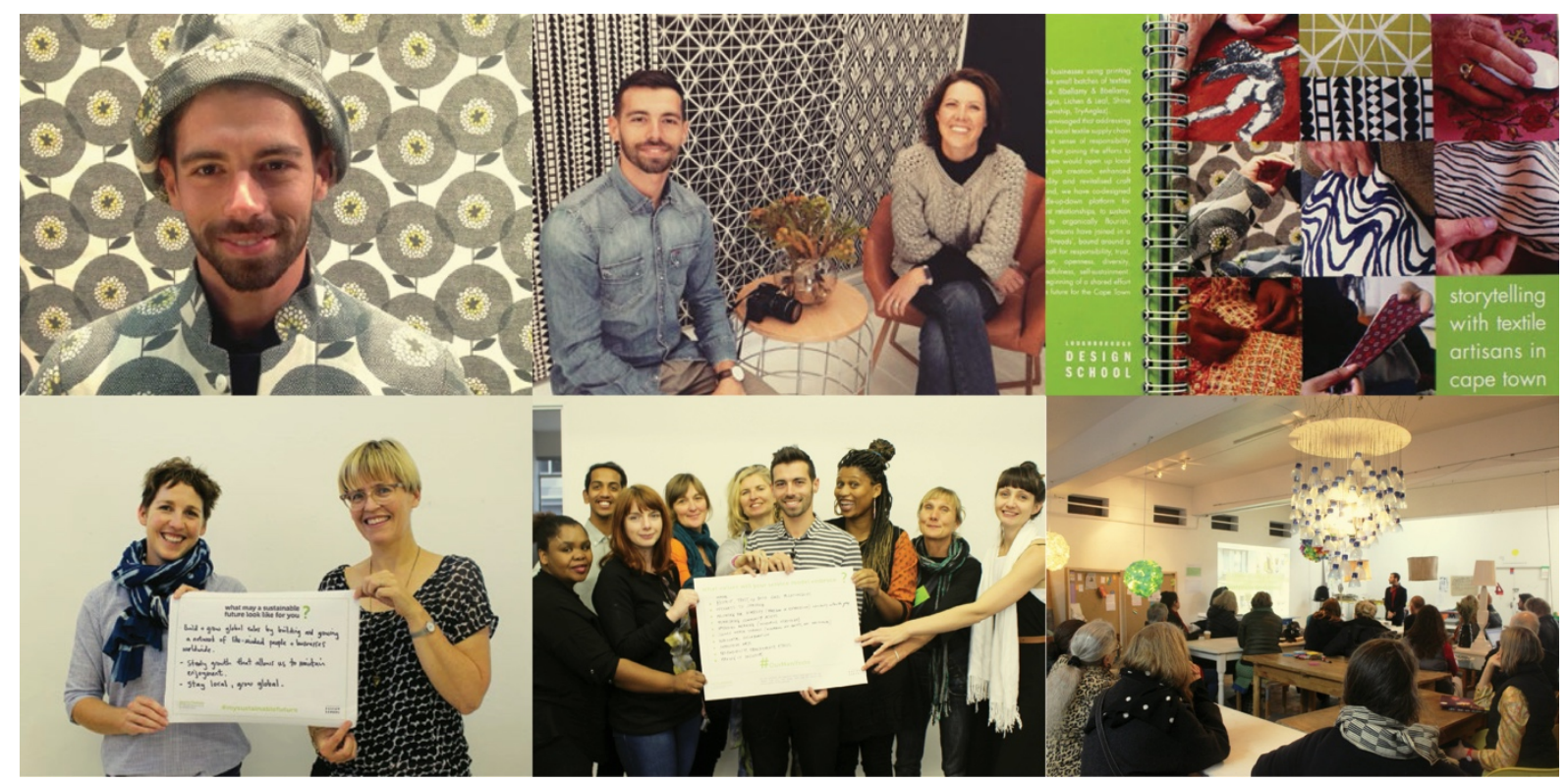

Figure 3: Snapshots from the Cape Town case study.

The anthropological approach adopted in the Cape Town case study equipped the design researcher with cultural sensitivity to discover the locale and situate the service design intervention within a group of artisans motivated to participate in the co-design of a meaningful social innovation. The context immersion evidenced that the shortage of fabric manufacturers had mobilized the creativity of artisans to start-up businesses focused on printing on local base cloth, in order to differentiate their textiles over competitors, while contributing to job creation and cultural heritage preservation. Through storytelling, the designer was able to map out the patchy artisanal landscape in Cape Town, challenged by social inequalities within businesses mostly managed by white women, while the majority of black people work from townships and have poor access to development programmes. The main challenge emerged to be the shortage of local fabric supplies and CMT (Cut, Make, and Trim) skills, since the information is not shared amongst businesses. The study also enabled the artisans to envision a sustainable future, framed as a quest for making the local economy flourish through a peer-to-peer network of like-minded businesses and a wider support system, contributing to job creation and perpetuating heritage know-how into future generations. Sensemaking evidenced an upsurge of product customization and social enterprises, as well as the importance of enabling ecosystems for the development of local artisanal businesses. Through co-creation, the artisans turned their challenges into opportunities for service innovation. Instead of waiting for governmental aid, the participants outlined a 'middle-up-down' strategy, conceived as a synergy of 'bottom-up' initiatives and a 'top-down' support system. In this regard, one artisan stated: "The need for systemic change is very important in South Africa nowadays. This would lead to organic growth, starting from grassroots innovations, and letting people recreating the sector, without waiting for top-down support, which may come too slowly". A stakeholders' network was mapped, at the core of which the artisans - united within the 'Weaving the Threads' collective - were placed, supported by a middle manager. The collective was intended to overcome the artisans' feeling of isolation, as one participant proposed: "if we get together, we make an agency of textile artisans". A situated 
service proposition was outlined as an open access platform for sharing information throughout the supply chain, supported by offline events, collective showcases and strategic meetings in the artisans' open studios. A manifesto was co-designed by the artisans sharing core values (i.e. responsibility, trust, sharing, collaboration, diversity, flourishing, slowness, self-sustainment, and inclusivity) to be embedded into the service innovation process. Through a roundtable discussion, the creation of a support network of stakeholders was facilitated, activating a legacy within the local community.

In summary, the Cape Town case study highlighted the need for the designer to be sensitive to local cultures as a way to scope a meaningful intervention within a context. This context-aware way of entering a community allowed the designer to give voice to artisans at the "bottom of the pyramid' and interweave the fragments of their tacit knowledge into compelling narratives. Such an approach also contributed to empowering the artisans to start thinking openly and creatively about sustainable futures; by framing visions which were meaningful to them, the artisans became agents of their own alternatives. By turning their challenges into opportunities for the future, the artisans felt driven to take collective action grounded in values shared within the community. Building a 'middle-up-down' support network of diverse stakeholders also emerged as an enabling ecosystem aimed at making the community become resilient over time. Finally, the study emphasized the importance of the designer activating a legacy within the local community for the artisans to progressively take ownership over follow-up initiatives.

\section{Discussion of the 'Crafting Situated Services' Framework}

The 'Crafting Situated Services' framework illustrated in Figure 4 outlines the diverse roles that the service designer can play and the methods and tools which can be used to achieve specific purposes throughout a social innovation journey. More details of the different tools can be found in the Appendix. The framework comprises a range of elements (i.e. roles, purposes, methods and tools) to aid the designer in entering communities (Section 5.1), building new narratives (Section 5.2), making sense of sustainable futures (Section 5.3), co-designing situated services (5.4), and activating meaningful social innovations (Section 5.5). The framework is visualised as an adaptation of the widely used double diamond developed by the Design Council (2011) and recently updated as a systemic design approach (Design Council, 2021). Whilst drawing from the latter some key principles, roles and activities, the framework here presented enriches it by outlining a set of roles, purposes, methods and tools which can be enacted throughout a social innovation journey, and it problematises it by discussing key issues for a designer to take into consideration when 'crafting situated services' with communities. The framework was conceived to be flexible and open to adoption and adaptation by other designers, drawing on the resources and situated knowledge of local stakeholders in order to activate an on-going and collaborative process of change. It goes beyond the focus on a set of methods and tools on which service design practice has been legitimised as a disciplinary field (Sangiorgi and Prendiville, 2017), and recognises the action-oriented (Anderson et al., 2018) and multidisciplinary (Joly et al., 2019) contribution of service design. 


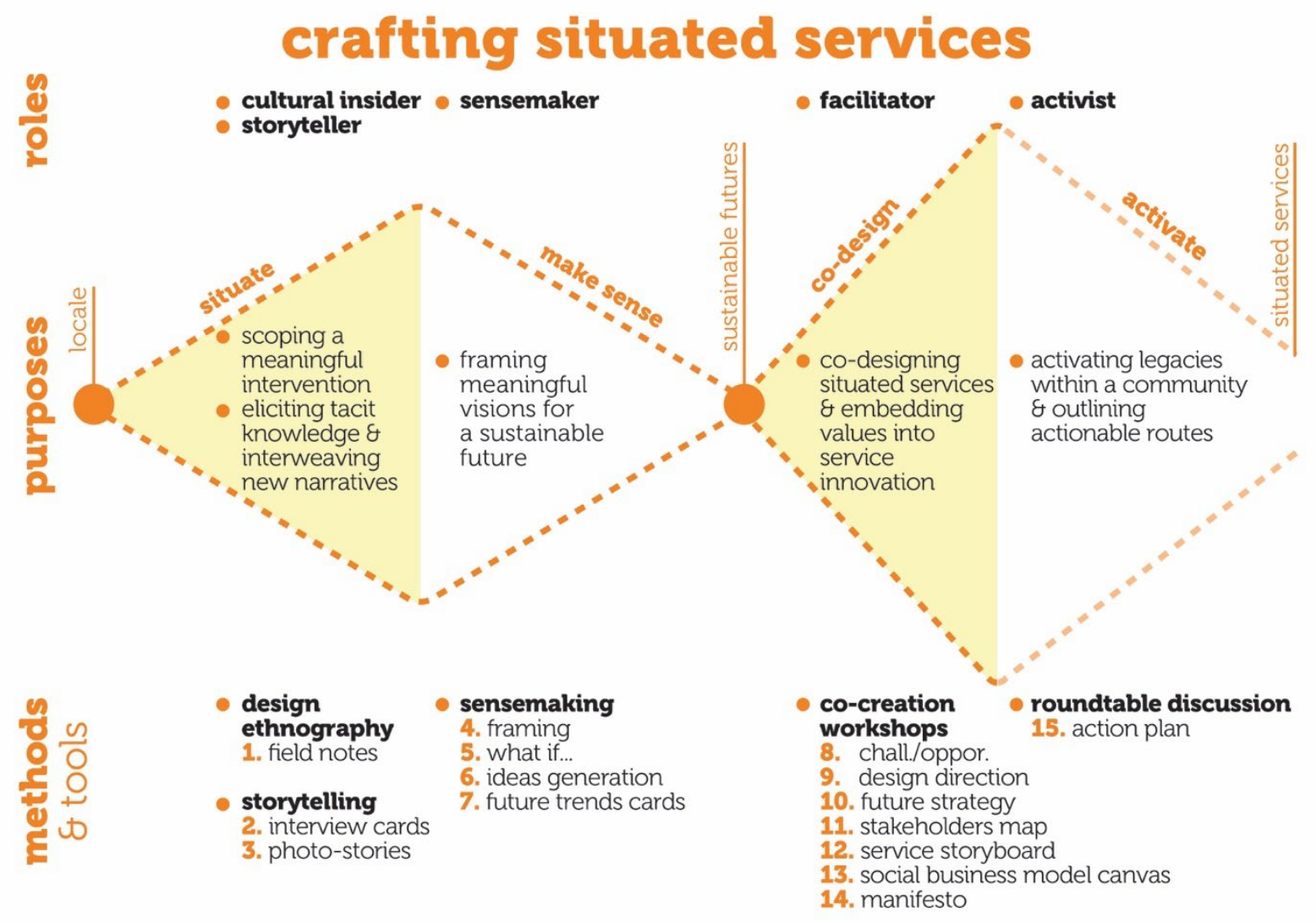

Figure 4: The 'Crafting Situated Services' framework.

\subsection{Tackling the Designer 'Parachuting' Approach to Entering Communities}

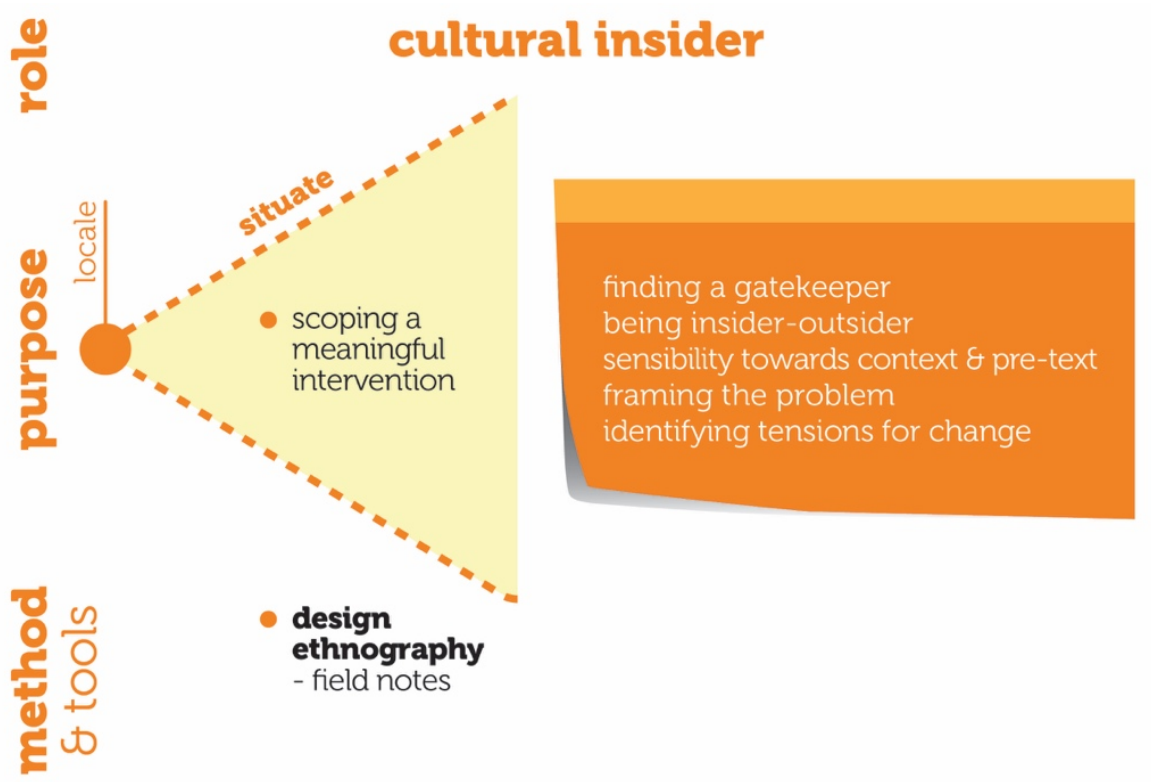

Figure 5: The 'situate' stage of the framework.

The initial stage of the framework (Figure 5) argues for the need for designers to go beyond 'empathy' (Cipolla and Bartholo, 2014) and play the role of a 'cultural insider' able to establish a dialogical relationship with a community. This addresses the limitation designers face to grasp the 
complexity of local contexts (Penin et al., 2016), and the inefficacy of 'parachuting' into communities (Akama and Prendiville, 2013). Building on design anthropology (Gunn and Donovan, 2012), the framework allows gathering of sociocultural insights which are often overlooked by 'top-down' support organisations when devising aid strategies for artisans and communities at the 'bottom of the pyramid' (Prahalad and Hart, 2002).

The two case studies also highlighted that the way stakeholders perceive the role of design influences the way they engage in collaborations. One example occurred in the participant recruitment stage. Whereas in Nottingham the design researcher experienced resistance to collaborate, in Cape Town an initial design ethnography activity was conducted in order to identify a 'gatekeeper' - also defined by Morelli (2015) as a 'community provider' - to get access to participants, build on existing relationships and activate a chain of contacts motivated to take part in a co-design process.

The framework shows the strength of using design ethnography - through participant observation and unstructured contextual interviews - in order to deeply understand not only the context of intervention but also the 'pre-text'. This is a concept borrowed from Junginger and Bailey (2017) to refer to past design experiences, which are here embedded into the process of service innovation. In particular, this stage of the framework aids the designer in identifying 'tensions for change', meaning challenging situations which can be turned into opportunities for innovations, which are meaningful and compatible to local cultures. For instance, in the Cape Town case study, the context immersion activity contributed to eliciting a series of sociocultural issues (e.g. racial segregation, competitive business mindsets, difficult access to developmental resources, and inefficiencies within the formal sector). These were framed from the perspective of different target groups (e.g. the unemployed, black people, white business owners, social enterprises, and government) whose worldviews and agendas were taken into consideration while co-designing a meaningful social innovation. Although the value of such a pre-incubation stage within a social innovation journey is often underestimated in comparison to the generation of solutions, it is equally needed in order to activate a collaborative process of change.

\subsection{Interweaving Fragments of Past and Present into New Narratives}




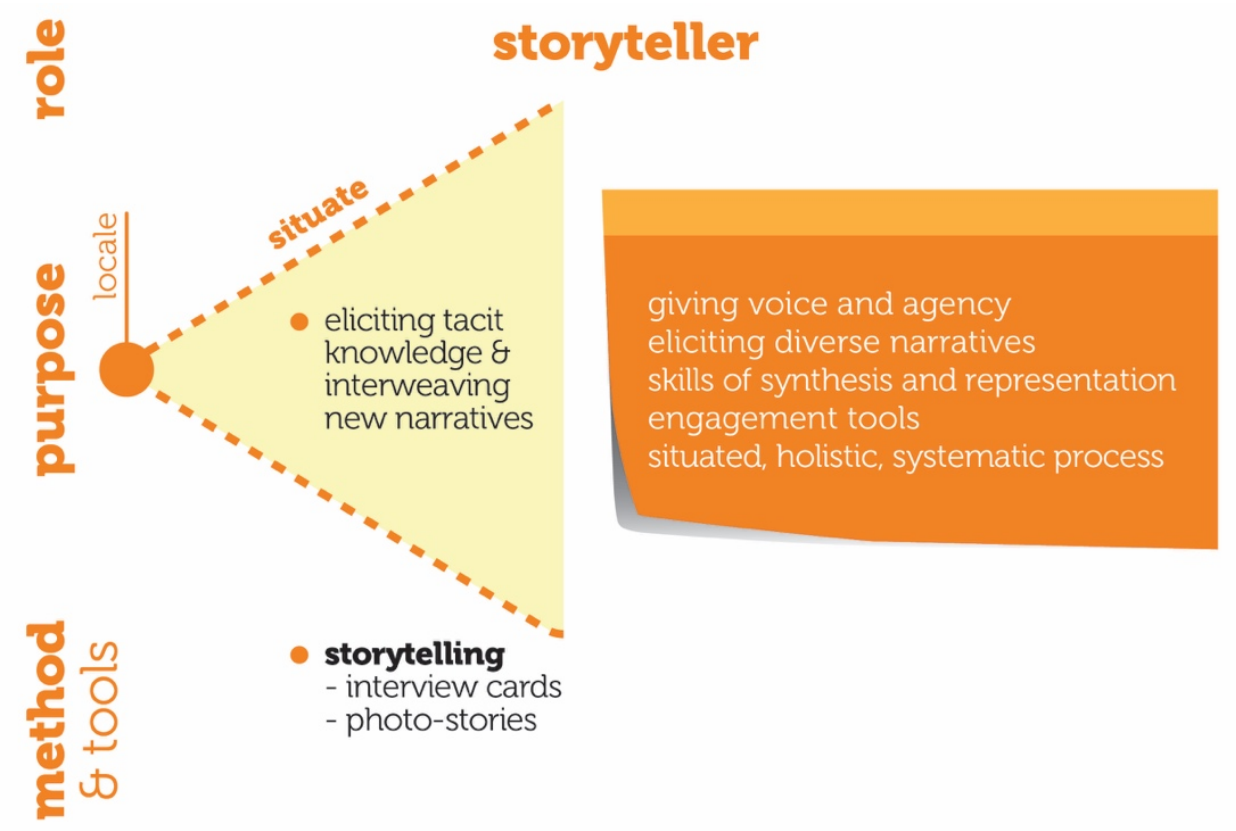

Figure 6: The purpose, method and implications associated to the 'storyteller' role of the designer.

This stage of the framework (Figure 6) refers to the role of the designer both as a story-listener (Valsecchi et al., 2016) - eliciting the artisans' tacit knowledge - and as a storyteller (Tassinari et al., 2015) - interweaving fragments of community practices into new and compelling narratives. This requires 'deep listening', i.e. being actively receptive and establishing a researcherparticipant relationship based on trust, professionalism, availability, openness and sharing. This way, the artisans participating in the two case studies - who initially felt marginalised - had their voices heard and gained agency within the local community.

The framework proposes adopting a phenomenological approach to challenging a blind faith in a linear progress towards 'the' future, and instead adopts the metaphor of 'lines' introduced by Ingold (2007). This emphasises a continuous movement between past, present and future temporalities, in which multiple voices can emerge, carrying diverse experiences, fears, and aspirations. For instance, when interweaving fragments of past and present practices into visions for sustainable futures, tensions emerged in the Nottingham lace artisans' claim that maker skills were being lost whilst they showed a lack of willingness to employ and train more people.

Similarly, despite the artisans' quest for further support from organisations in Cape Town, many businesses had not made much use of the resources provided by such institutions. The approach proposed in this framework is meant to be mindful of pre- and post-design legacies (often overlooked by 'top-down' organisations when providing support services) and oriented towards envisioning sustainable futures (instead of using ethnography to merely serve a documentary purpose).

To counter the criticism around storytelling being often used in an 'intuitive' way by designers attempting video-making to document their research (Bertolotti et al., 2016), the proposed framework ensures a more systematic process. Storytelling cards are used in this stage to aid the designer in conducting contextual interviews, complemented by observations and photography in order to capture contextual insights, which would be otherwise overlooked in non-contextual 
interview settings. As an outcome, a photo-story can be designed to capture, through photographs and a diary-like text, intangible insights and make them tangible through the designer's skill of synthesis and representation. Photo-stories can also be used as 'engagement tools' (Thorpe et al., 2016) to trigger debate and exchange amongst stakeholders in the process of co-designing situated services grounded in the stories of the artisans and the local heritage.

\subsection{Making Sense of Sustainable Futures within the Artisans' Realities}

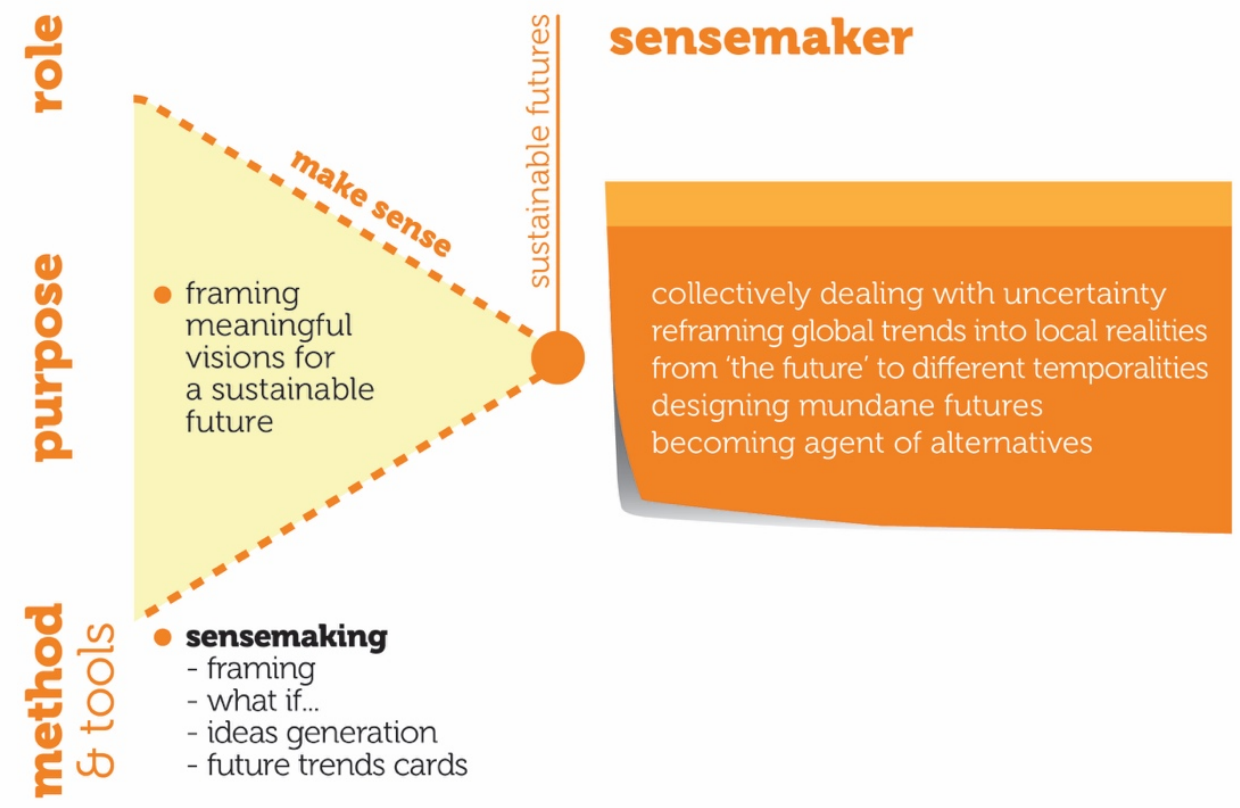

Figure 7: Key implications associated to the role, purpose and method of the designer as a 'sensemaker'.

The subsequent stage of the framework (Figure 7) introduces the concept of sensemaking initially developed in organisational sociology (Weick, 1985) - into the field of service design for social innovation. The framework contributes to 'democratising' design thinking, by taking the responsibility for finding the best solution away from the designer and proposing instead sensemaking as a co-created way to frame social innovations that are meaningful to local communities. Building on Smith et al. (2016), the framework shows that adopting a design anthropological approach to future-making is necessary to preserve and revitalise local traditions and cultures, such as those embedded into artisanal products.

Throughout the two participatory case studies, the artisans' visions for the future focused upon socioeconomic sustainability. This evidences that, social innovations still need to find their own sustainability models, alternative to the mainstream system. In fact, by unpacking the concept of 'sustainable futures', the artisans expanded their understanding from overwhelming environmental concerns and gained motivation towards taking collective action towards socioeconomic flourishing. The textile artisans participating in the Cape Town case study framed their vision for a sustainable future as an opportunity for making the local economy flourish through job creation and conveying heritage know-how to future generations by building a network of like-minded businesses and a wider support system. This demonstrates the ability of design thinking methods to promote (sustainable) innovation (Yu and Sangiorgi, 2018). 
This stage of the framework includes sensemaking activities, which help shifting from contextfree future trends towards human-scale visions for the future situated into the participants' realities. For this purpose, existing tools (i.e. 'framing', 'what if...', 'ideas generation') are adapted and 'future trends cards' are specifically designed to help artisans frame their visions for a sustainable future, map out what would happen to their businesses if some future trends occurred, and generate new ideas to inform the co-design of a situated service. Although aware of the possibility of conducting collaborative sensemaking (Raijmakers et al., 2013), the designer in both case studies exercised sensitivity towards the artisans feeling in a vulnerable condition, and engaged with each business separately in order to create a comfortable atmosphere for the participants to share their own fears and aspirations for the future. Instead of recommending that the designer adopts a 'top-down' 'helper' attitude, the framework encourages participants to become 'agents of their own alternatives' (Fuad-Luke et al., 2015) and challenges the commonly passive attitude of communities waiting for 'top-down' support from external organisations.

\subsection{Facilitating the Process of Crafting Situated Services}

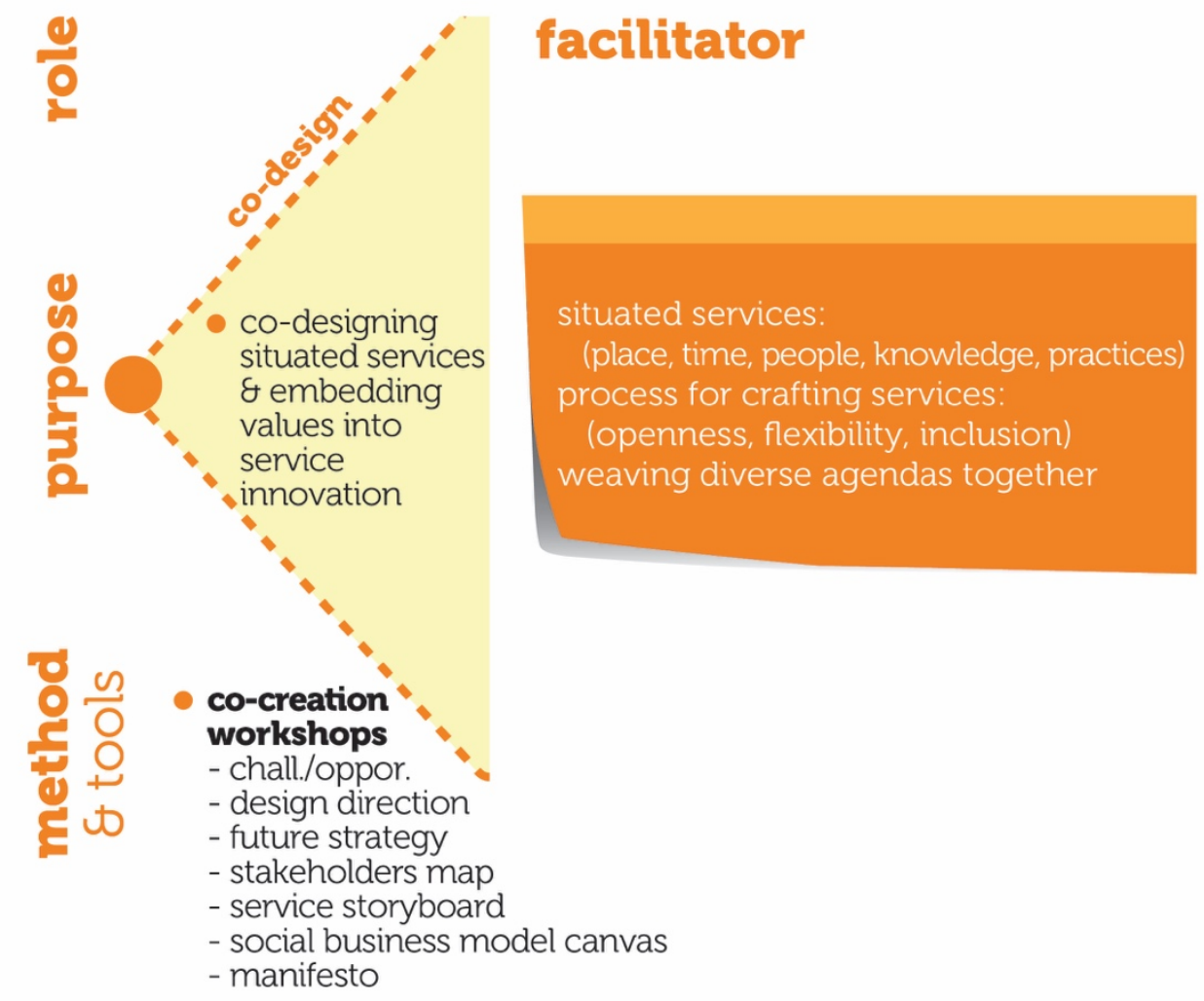

Figure 8: The role, purpose and method of the design 'facilitator', with the key implications for 'crafting situated services'.

The subsequent stage of the framework (Figure 8) expands the much-discussed 'facilitator' role of the designer and emphasises the political role of the designer (Mazé, 2014), having to deal with people with diverse agendas and conflicting visions for the future. In the two case studies, the designer, being an 'insider-outsider', was not perceived by the artisans as a competitor, but created the conditions for a co-creation process to occur, zooming out from short-term and individual challenges to long-term opportunities for the wider community to contribute to place- 
making. For instance, in the Nottingham case study, although the proposition of a 'co-designer in residence' was conceived to provide bespoke and situated services for innovation of individual artisanal businesses, an overarching strategy was negotiated around the collective purpose of recreating a sense of place.

The framework demonstrates the value of using aspirational tools, such as the manifesto of values, which allows embedding of sociocultural issues into service innovation processes. As an outcome, the designer can bring individual artisans - whose practice is dying out also due to their isolated condition - together as a community, grounded in an alignment of values. The activation of the artisans' community was crystallised in the Cape Town case study by using photography. The artisans were initially photographed individually holding posters framing their own visions for the future, then all together holding their community values' manifesto, and finally with the designer among them, having brought their collective to life. Adopting such an approach, the case studies led to the outline of situated service propositions aimed at transitioning the local textile artisan communities towards sustainable futures.

Building on Prendiville's (2015) anthropological perspective on the concept of 'place', the framework makes an explicit introduction of the concept of 'situatedness' in the field of service design for social innovation, disrupting the limitation of replicating services across contexts, regardless of their integration into local cultures. Here services are defined as 'situated' when deeply rooted in a place and mindful of different notions of time, when their features are tailored to the needs of the people who use and produce them, and when local tacit knowledge and everyday practices are embedded within them. Moreover, the framework proposes a process for 'crafting situated services'. This requires the designer to be open to cultural sensibilities, flexible to navigate uncertainties, and inclusive to engage stakeholders both in the design of service outputs and in the process of co-designing them. This also contributes to a shift from a usercentred to a 'context-centred' approach (Santamaria, 2017), focused on the sociocultural context shaping the service, going beyond the operational and technological concerns of most service engineering scholars focused on the processes and outcomes of innovation.

\subsection{Activating Legacies within Local Communities}




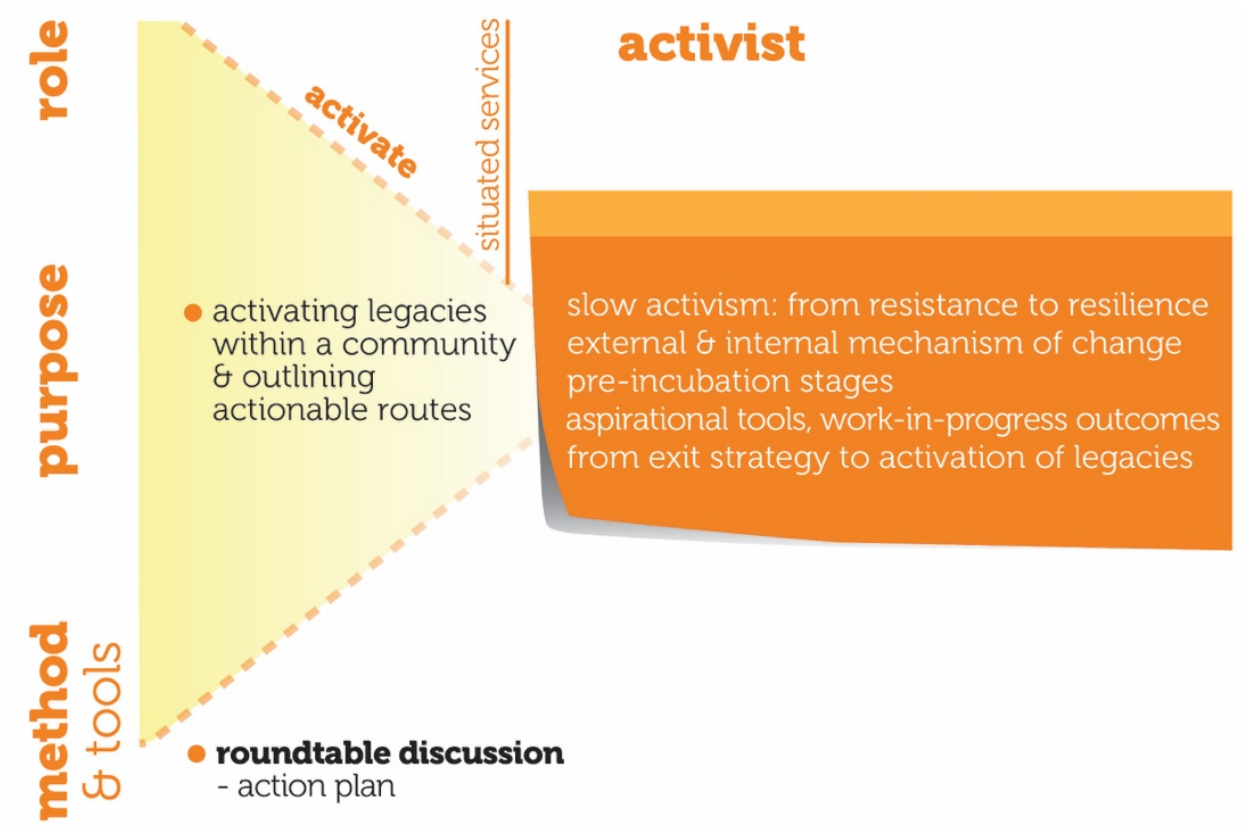

Figure 9: The role, purpose, methods, and key implications associated to the designer as an 'activist'.

The final stage of the framework (Figure 9) proposes ways for the designer to responsibly activate legacies within local communities so that they can gradually become independent in the adoption of a service design solution and guided by a local reference person in the implementation of a service. Going beyond the notion of 'exit strategy' (Meroni et al. 2013) - which carries with itself a sense of closure for the participants and of guilt for the designer - the framework emphasises the importance of activating long-lasting legacies within communities, even beyond the initial funding and timeframe of a project. With this in mind, the framework is visualised with an open shape and a gradient to represent an open-ended process in which the designer's contribution progressively dissolves, and actionable routes are outlined for the community to transition towards a sustainable future.

Instead of proposing a disruptive or speculative approach, the framework shows the strength of 'slow activism', an approach borrowed from Pink (2015) and used here to overcome the artisans' resistance to innovate and move towards community resilience and co-ownership of the innovations. For instance, in the Cape Town case study, for reasons of survival, the artisans were better equipped to risk and innovate than in Nottingham, where the local stakeholders were disheartened about their future, and therefore the designer had to play a more proactive role in facilitating a future-making process. This is an interesting twist on the notion of inclusion discussed by Fisk et al. (2018, p. 844), where a foundational pillar of inclusivity is "empowering people by providing access to services and the ability to receive and co-create valued services". The framework similarly identifies how the provision of 'empowerment' for the long-term sustainability of the artisans must be inclusive of their propensity to take independent action within that journey of empowerment, and therefore their need for varying levels of intervention by the designer. 
Among the methods available in the design activist's palette, roundtable discussions are proposed as a means to foster synergies among different stakeholders and activate meaningful social innovations. A concrete example is the roundtable discussion conducted towards the end of the Cape Town case study, which was not conceived as a viability or feasibility test, but as an engaging event that provided a neutral space for activating a new form of collective 'middle-updown' management across diverse stakeholders. It also contributed to identifying a member of the local University as a reference person empowered to enable the implementation of the service and facilitate online sharing of insights and feedback with the researcher after he physically exited the community.

Building on Sangiorgi's (2011) theory of 'transformation design', the framework emphasises the need for developing an enabling ecosystem based on both external 'mechanisms of involvement' of diverse stakeholders and on internal 'mechanisms of change' around shared values. This was evidenced in the service proposition outlined in the Cape Town case study, which goes beyond the bilateral user-provider relationship of services and involves a more complex support network. In this process, the focus is not on delivering service outputs that bring closure to the designer's engagement with the community, but on outlining actionable routes towards a sustainable future. This supports the action-oriented perspective of design described by Anderson et al. (2018). The results of such a process are less formal than commonly fixed service blueprints but are conceived more as 'work-in-progress', such as a service storyboard and a manifesto of values. In the two case studies, the manifesto encompassed not a set of instructions to be followed, but empowering statements, elaborated as an anchor for the artisans to join together around shared values and undertake a collaborative process of transformation, and open enough to allow the community to evolve. Furthermore, it emerged that the values underpinning the manifesto could be used by the artisans as criteria against which to assess the evolution of their own practices over time.

\section{Validation: The Value of the Framework for Service Design for Social Innovation}

The validation of the framework was undertaken via the evaluation study outlined in Section 3.3. The following sections discuss the original contribution of the framework to service design theory and practice, its relevance for tackling real-world problems, its extensibility, and the rigour of the research process.

\subsection{Contribution to Service Design}

The participants in the evaluation study acknowledged that service design is integrating approaches from other disciplines, and this mix of approaches was described as "methodologically interesting also for artisans, to embed service design into their processes"[P1]. One practitioner acknowledged that, while service design has become a consolidated approach in other sectors (e.g. healthcare, hospitality, mobility, policy-making), there are few cases of application of service design for social innovation within the context of artisanship. "Applying service design for social innovation in the context of artisanship can be done, and it is interesting to do it, but I don't know how we can do it. If you have the opportunity [for knowledge exchange], come here!"[P2]. In recognising the value of the framework, one practitioner stated: "It will surely help getting in touch with local stakeholders and explaining in a more structured way the complexity of design 
for social innovation projects. This framework, with academic background and examples, could help us reach our goals faster, explain things in a more tangible and practical way"[P3]. In fact, in some projects, designers face resistance when engaging local stakeholders who are sceptical in trusting and adopting new service design processes; instead, the 'crafting situated services' framework was judged to provide an original methodological approach, supported by academic research and practical case studies.

\section{- Expanding the Roles of the Service Designer}

One service design practitioner was interested in the different roles highlighted in the framework, and particularly the activist role of the designer. In this regard, he stated: "The service designer can surely be an anthropologist and storyteller, a sensemaker by developing his/her own sensitivity towards an issue, a co-creator because that's what he/she is supposed to do even in the traditional commercial service design field, but can he/she be an activist? [...] It takes a leap beyond what a service designer is generally doing in community work"[P3]. The framework also supports the role of the designer as a coordinator of a multidisciplinary team of people applying their specific skills at different stages of the social innovation journey, as highlighted by one project manager working in a third sector organisation: "It could be a way for a designer to coordinate and lead that process, with different people coming along at different points"[P4].

\section{- Introducing a Situated Approach to Service Innovation}

The evaluation study highlighted that the framework brings "a great example of how a cultural sensitivity can be embedded into service design" [P1]. The framework is not conceived as a toolkit imposed on stakeholders, but a flexible, tailored and nuanced approach: "I value this anthropological approach because being an insider in a community means being sensitive to the power dynamics of the design process [...] and to the fact that certain tools and approaches will be more suitable to some participants and not to others"[P5].

Participant 1 described how the term "situated services is a very powerful concept. [...] This term draws on different traditions, and you are bringing them to service design. [...] When you craft situated services, you bring a lot of local cultural values into services. [...] There is a lot of discussion around services related to economics and marketing that are about reproducing services. Instead, you are embedding the concept into a local level”. Participant 3 recognised the importance of a co-design approach: "The framework you are presenting is discouraging the 'topdown' approach to innovation of service designers coming up with an idea that can be 'copied and pasted' from somewhere else in the world. [...] It is encouraging a more open discussion, by identifying early in the process the right gatekeepers who could lead to the right stakeholders and, at that point, it activates a process of co-creation".

\section{- Proposing a 'Middle-up-down' Approach to Social Innovation}

In the project discussed in this paper, the designer did not propose a 'top-down' agenda but was also not a member of a community designing a social innovation from the 'bottom-up'. Instead, the designer acted in a 'middle-up-down' role in order to address issues of sustainability and scalability of social innovations, as emphasised by the cultural anthropologist interviewed for the 
evaluation study: "I see the service design anthropologist as a bridge. [...] To be effective, you need to have skills to deal with both decision makers and people on the ground"[P5].

\section{- Expanding the Remit of Design for Social Innovation Towards Design for Social Entrepreneurship}

Participant 3 identified the opportunities (and challenges) for a service design approach to be adopted by social enterprises in order to tackle complex social challenges: "In the commercial world, a service designer is the person who designs services and brings expertise, but he/she is not the entrepreneur who started the project off. Instead, in the social design field, if you take the role of the service designer as the person who activates social innovations, that means that he/she is more than a designer; he/she is a change-maker". The same interviewee highlighted that such an expanded role contributes to the professional growth of the designer and the economic sustainability of service design projects, for instance by developing sustainable business models and scaling strategies.

Moreover, participant 1 emphasised that this research project contributed to expanding the remit of the service design discipline within the wider service science, as it bridged two commonly distant domains, i.e. the field of service management with that of service design for social innovation. It does so by proposing a 'designerly' way of working with businesses in order to activate social transformations and enhance a sense of place. "Your work is creating a bridge from those who come from a managerial and marketing world to understand how service design can serve a social purpose" [P1]. However, the whole research project and related evaluation study were framed mostly within the scope of service design, but more work is needed to further investigate the service manager role as well as related challenges and opportunities.

\subsection{Relevance for Tackling Real-World Problems}

The following sections report on the key findings from the evaluation study in relation to the theme of 'relevance' borrowed from Zimmerman et al. (2007) as one of the criteria for evaluating design research.

\section{- Minimising the Limitations of the Designer 'Parachuting' Approach}

The evaluation study highlighted the relevance of the 'crafting situated services' framework to minimise the problem of the designer 'parachuting' into communities. Participant 1 highlighted that the context immersion proposed in the framework contributes to expanding the focus of participatory design from empathy towards inclusion. "You were alleviating the fact that you were external. [...] You have contributed by saying 'I am not only having empathy, but I am having a deeper cultural sensitivity and pursued a process that made me more aware of what the community was like'. [...] This is the highest level of designers not being parachuted in a community, but really being there. [...] Instead of being binary opposites, we are talking about different grades of sensitivity"[P1]. In this regard, the framework emphasises the need for designers to put considerable efforts into building trust and mutual understanding with the participants, creating a comfortable environment for the participants to share their stories (in 
storytelling sessions) and open themselves up to think about the future (through sensemaking activities).

One participant (with a background in cultural anthropology) corroborated that the efforts invested by the design researcher to immerse himself into communities were a suitable adoption of an anthropological approach to service design. "The main objective of the ethnographer is to get the natives' viewpoint. [...] Your framework makes a lot of sense. Learning from the community, framing the problem, then formulating the design and validating it with the community is a very sound way to go about it [design anthropology]"[P5].

\section{- $\quad$ Giving Hope and Activating a Process of Thinking Creatively About the Future}

The study emphasised that the framework is particularly relevant to support designers in helping vulnerable people gain hope that more positive alternatives to their current situation are possible. The framework was also deemed relevant to enable non-creative types of people to engage in a process of thinking creatively about the future. "What really struck me was that you tried to engage the artisans explicitly in a conversation about the future. [...] This would be really helpful, because most of the times people who are new to service design really struggle to go beyond what's already available and think about the future in a creative way"[P4]. Moreover, the tools adopted for the sensemaking sessions were judged particularly useful in visualising the participants' visions for the future and the potential for innovation: "The part that can make a contribution to my own projects lies mostly in the situate' part of the framework. This part could help me gain a better understanding of the stakeholders' vision of their own potential. [...] In my own experience, we tend to make informal [verbal] conversations with stakeholders, so using the methods and tools that you propose that are more visual, will be better"[P2].

The potential for shifting between current and future timescales in order to overcome resistance towards change was highlighted by Participant 4: "It is actually in that longer-term future where you could get more agreements between different people with different agendas. [...] The longerterm future could be a nice way of creating some alignments before you have conflicts emerging. I do not think you can get rid of that, but you could start from something positive and get people - who could be strongly disagreeing on things - to think together about that longer-term future".

\subsection{Transferability to Other Contexts}

The participants in the evaluation study assessed how the 'crafting situated services' framework could be applied not only to textile artisanship but also to other sectors in order to make further contributions to the service design field.

\section{- $\quad$ A Model for Engagement with Communities}

Participant 4 highlighted the usefulness of the framework to work with other types of marginalised groups: "It would be really useful to the work I do with marginalised groups. [...] If you get to the point when they can talk about the future, and think openly about that future, to be really different from what it is now, there is a lot of work to do together". The framework was also judged useful to facilitate engagement between currently disconnected members of communities, for example empowering citizens (with diverse backgrounds and aspirations) to 
make meaningful use of open data. "The framework would be interesting in my project where we try to put together communities with different expectations, cultures and so on; there, especially the first diamond of your framework, becomes very relevant"[P6].

\section{- Application of the Framework in Public Sector Organisations}

The framework was recognised as a model elaborated from the 'double diamond', which is familiar to designers but also managers of organisations using design thinking. Participant 4 stated that: "although the framework speaks very clearly to designers, it could be used by other roles too. [...] It would be very helpful for me, as a project manager of an organization in the third sector, which works in the field of social innovation". Another service design practitioner was interested in its application in the public sector: "I would be very curious to see how your framework could work in the public sector, intertwining the community-based approach that you are suggesting with some of the policies of local authorities. [...] I think this would add a whole level of complexity, in terms of policy discussion, but I can see that your framework could address that as well. It could become a very interesting framework for public consultation, which for sure will make your work very relevant for many public administrations"[P3].

\subsection{Rigour of the Process and Potential Issues with its Outcomes}

Discussing how they could adopt or adapt the 'crafting situated services' framework to their own design research and practice, the interviewees assessed the rigour applied to the process and outlined potential issues related to the outcomes of the research.

\section{- A Set of Existing Tools, Repackaged into a Flexible Framework}

The interviewees highlighted that the tools proposed in the framework already exist; however, the contribution of the project presented in this paper lies in the original way of bringing them together into a meaningful and effective framework. "In my experience, if you want to work on design for social innovation, you have to build on a very rich toolbox and learn to use the tools in different ways"[P6]. The interviewees also stressed the need for tailoring the methods to address specific purposes in different contexts (as had been done in this project).

\section{- $\quad$ Challenges in Adoption and Diffusion of the Framework}

To overcome the specificity of the design language used, and to enable the framework to be adopted and adapted by others in their own contexts, one interviewee recommended to further explain how to use the different tools and overcome any challenges encountered, as well as to add practical details about the timeframe, costs and resources required throughout a social innovation journey. "How would you help people navigating tools coming from different disciplines? [...] When I have been using design, even something standard like the 'double diamond', there has always been an issue, like time, resources, skills, the cost for the organisation"[P4]. One design practitioner also recommended producing a video in order to present the framework and how it works in a more accessible and engaging way in order to diffuse it online to a wider audience.

\section{- Lack of Service Implementation, Going Beyond Facilitation of Co-design}


A service design practitioner emphasised the need for the design researcher to go beyond the use of tools during co-creation workshops. Even if provided with instructions and support, it is unlikely that stakeholders can use the tools independently, in a meaningful and effective way. A proposed solution was to build capabilities in a few key stakeholders and empower them through mentoring on a medium-term basis - to become cultural insiders sustaining the project in the long-term. "The risk could be that in many projects we introduce a lot of tools and frameworks that are usually well received. If they are used just during workshops, it is difficult for people to implement change and continuously improve their services in the future. It is about long-term legacy, and not only passing on the attitude and the mindset, but also some practical tools" [P3].

Another issue that emerged from the study was the need for local communities to take responsibility for the implementation of the service propositions. "How did you help a designeror whoever is left with the vision of the future and the action plan - to make sure that it is actually implemented? [...] What happens after the plan is an area easily overlooked. [...] Maybe there is a next step for going back to your artisans, and looking at how they have managed since you have left, what they have done"[P4]. This was recognised to be a recurring challenge in any social innovations activated by a designer, posing the need for creating an infrastructure or enabling ecosystem to sustain social innovations over time.

\section{- Lack of Evaluation of the Social Impact}

The experts interviewed also highlighted a need for identifying relevant quantitative and qualitative impact criteria. These could include concepts such as empowerment and resilience. "It would be useful to see alternative ways of evaluating; this does not always mean trying to define the indicators that could monetise the impact, but you could maybe visualise the social value. [...] You need to show the numbers, but also the change in the lives of people. You could do a documentary, but that's not always easy to do"[P3].

\section{Discussion and Conclusions}

One of the key theoretical contributions of this paper lies in making an explicit introduction of the concept of 'situatedness' in the field of service design for social innovation, and proposing an original methodological framework for 'crafting' such services according to the local context. The paper also advances an anthropological approach to service design, overcoming the limitations faced when services are conceptualised from a business or engineering perspective, often overlooking the social world underneath innovation processes, as argued by Blomberg and Darrah (2015). It addresses the lack of attention to service design and innovation identified by Patrício et al., (2020) and provides an alternative, more process-focused and role-centred perspective than the framework developed by Alkire et al., (2019). Based on the evaluation study, it was possible to conclude that the project contributed an original framework that aids the service designer in entering communities and co-designing situated services that activate social innovations meaningful to them. The project supported the claims that service design can aid transformation due to its action orientation (Anderson et al., 2018) and that design thinking is effective for crossdisciplinary service innovation (Yu and Sangiorgi, 2018). The studies presented in this paper 
demonstrated the multiple roles (i.e. as cultural insider, storyteller, sensemaker, facilitator, and activist) that the service designer can play throughout a social innovation journey. Borrowed from business literature (Nonaka, 1988), the concept of middle management is further developed in this paper into a 'middle-up-down' approach to design, which overcomes challenges in terms of sustainability of 'bottom-up' social innovations and 'top-down' strategies that do not meet the specific needs and aspirations of diverse local communities. Findings from the studies presented in this paper suggest that the research advances the field of service design from design for social innovation to design for social entrepreneurship and makes a bridge between two service design domains (i.e. service management, and service design for social innovation). The research here presented links service design to the wider service science within which societal transformations are embedded. The 'crafting situated services' framework was judged as a relevant way to minimise the negative impact of (Western or Western-trained) designers 'parachuting' into disadvantaged communities with the assumption that they can bring their own knowledge and expertise to solve their problems. In line with Turnstall's (2013) argument of design anthropology as a decolonised methodology, the case studies discussed in this paper demonstrate respectful engagement with community values and the adoption of an inclusive approach to co-design. The evaluation study also recognised that the framework has broader applicability, and could be used within diverse communities or sectors in need of transitioning towards a more sustainable future.

\subsection{Recommendations for Future Work}

In view of future academic and professional avenues, a need to establish and integrate impact measures relating to social innovation emerged from this research project. Over the short-term, these could have feedback mechanisms that enable choice or adaptation of creative methods. Over the longer-term, these would indicate whether the transformative potential of service design is being realized. Moreover, in order to facilitate the adoption and diffusion of the framework amongst other designers and non-designers, a narrative or framing around its current visual representation could be added; this should also be supported by training the skills necessary for crafting situated services for social innovation. It is also recommended that the broader application of the framework is investigated further; for example, the potential to apply it to the scaling of start-ups or the training of students as the future generation of makers. In educational settings, bringing Fashion and Textile Design (or other craft practices) and Service Design students together is recommended to encourage systemic innovative thinking and build transdisciplinary collaborations. There is also scope for broadening the service designer's role further and exploring the role of the service manager activating artisan communities, and the challenges and opportunities related to that. Beyond empowering communities and co-designing collaborative services, the service designer could become a manager of social enterprises, adopting 'middle-up-down' approaches to sustaining and scaling social innovations. Finally, it is envisaged that the 'crafting situated services' framework is applied more widely to address an important need in service design research, and used in practice and educational settings, making also a positive impact on society.

\section{References}


Akama, Y. and Light, A. (2012), A Candor in Reporting: Designing Dexterously for Fire Preparedness, in Proceedings of the $1^{\text {st }}$ Nordic Conference on Service Design and Service Innovation, 24-26 November 2009, The Oslo School of Architecture and Design, Oslo, Norway, pp. 1-11.

Akama, Y. and Prendiville, A. (2013), "Embodying, Enacting and Entangling Design: A Phenomenological View to Co-designing Services", Swedish Design Research Journal, Vo. 1, No. 13 , pp. 29-40.

Alkire, L. et al. (2019). “Transformative service research, service design, and social entrepreneurship. Journal of Service Management, Vol. 31 No. 1, pp. 24-50.

Anderson, S. et al. (2018). Transformative service research and service design: synergistic effects in healthcare. The Service Industries Journal, Vol. 38 Nos 1-2, pp. 99-113.

Baron, S. et al. (2018). "Feed People First: A Service Ecosystem Perspective on Innovative Food Waste Reduction", Journal of Service Research, Vol. 21 No. 1, pp. 135-150.

Blomberg, J. and Darrah, C. (2015), "Towards an Anthropology of Services", The Design Journal, Vol. 18, No. 2, pp. 171-192.

Bovaird, T. (2007) "Beyond Engagement and Participation: User and Community Coproduction of Public Services", Public Administration Review, Vol. 67, No. 5, pp. 846-860.

Briggs-Goode, A. and Dean, D. (2013), Lace: Here: Now, Black Dog Publishing, London, UK.

Brodie, R. J., and Peters, L., D. (2020) "New directions for service research: refreshing the process of theorizing to increase contribution", Journal of Services Marketing, Vol. 34 No. 3, pp. 415428.

Cipolla, C. and Bartholo, R. (2014), "Empathy or Inclusion: A Dialogical Approach to Socially Responsible Design", International Journal of Design, Vol. 8, No. 20, pp. 87-100.

Crafts Council (2014), Measuring the Craft Economy: Defining and Measuring. Craft Report 3, Crafts Council, London, UK.

Design Council (2011), Design Methods for Developing Services, Design Council, London, UK.

Design Council (2022), Beyond Net Zero: A Systemic Design Approach, Design Council, London, UK.

Dubois, A., and Gadde, L. E. (2002). Systematic Combining: An Abductive Approach to Case Research. Journal of Business Research, Vol. 55 No. 7, pp. 553-560.

Earley, R. et al. (2010), "Making Theory into Textiles through Sustainable Design Strategies, Pedagogy and Collaboration”, Brink, R. and Ullrich, M. (Ed.s.) (2010), Future Textile Environments, University of Applied Sciences, HAW College Hamburg, Hamburg, Germany.

Fisher, T. et al. (2016), "Using 3D Animation to Capture and Present Intangible Heritage: Industrial Textile Crafts". Furnace: The Postgraduate Journal of the Ironbridge International Institute for Cultural Heritage (IIICH), Vol. 3, pp. 1-8. 
Fisk, R. P. et al. (2018). "Design for service inclusion: creating inclusive service systems by 2050". Journal of Service Management, Vol. 29 No. 5, pp. 834-858.

Fuad-Luke, A. (2009), Design Activism: Beautiful Strangeness for a Sustainable World, Earthscan, London, UK.

Fuad-Luke, A. et al. (Ed.s.) (2015), Agents of Alternatives. Re-designing Our Realities, Agents of Alternatives, Berlin, Germany.

Green, J. (2013), “Beyond 20:2021 ${ }^{\text {st }}$ Century Stories”, available at: https:/www.growthintransition.eu/wp-content/uploads/Green-A-new-narrative.pdf (accessed 23 March 2020).

Ingold, T. (2007), Lines: A Brief History. London, UK: Routledge.

Joly, M. P. et al. (2019). "Leveraging service design as a multidisciplinary approach to service innovation”. Journal of Service Management, Vol. 30 No. 6, pp. 681-715.

Junginger, S. and Bailey, S. (2017), “Designing vs. Designers: How Organizational Design Narratives Shift the Focus from Designers to Designing", Sangiorgi, D. and Prendiville, A. (Ed.s.), Designing for Service, Bloomsbury, London, UK, pp. 33-47.

Kolko, J. (2012), Wicked Problems: Problem Worth Solving - A Handbook and a Call to Action, Austin Center for Design, Austin, TX.

Kvale, S. (1996). Interviews: An Introduction to Qualitative Research Interviewing. Thousand Oaks, CA: Sage Publications.

Manzini, E. (2015), Design When Everybody Designs. An Introduction to Design for Social Innovation. Cambridge, MA: MIT Press.

Manzini, E. (2014), “Making Things Happen: Social Innovation and Design”, Design Issue, Vol. 30, pp. 57-66.

Mason, S. (2010). Nottingham Lace: 1760s-1950s. Cluny Lace, Ilkeston, UK.

Mazé, R. (2014), “Our Common Future? Political Questions for Designing Social Innovation”, in Design Research Society 2014 Conference Proceedings, 16-19 June 2014, Umeå University, Sweden.

Mazzarella, F. (2018), Crafting Situated Services - Meaningful Design for Social Innovation with Textile Artisan Communities. (PhD Thesis) Loughborough University, Loughborough, UK.

Mazzarella, F. et al. (2017), "Crafting Sustainable Futures - The Value of the Service Designer in Activating Meaningful Social Innovation Within Textile Artisan Communities", The Design Journal, Vol. 20:sup1, pp. S2935-S2950.

Mazzarella, F. et al. (2018), "Weaving the Threads: Service Innovation with Textile Artisan Communities", in Proceedings of ServDes 2018: Proof of Concept, Politecnico di Milano, Milan, Italy. 
Meroni, A. et al. (2013), "Design for Social Innovation as a Form of Designing Activism. An Action Format", NESTA (Ed.), Social Frontiers, The Next Edge of Social Innovation Research, 14-15 November 2013, Glasgow Caledonian University, UK.

Meroni, A. and Sangiorgi, D. (2011), Design for Services. Aldershot, UK: Gover.

Meroni, A. and Selloni, D. (2018), "Design for Social Innovators”, Walker, S. et al. (Ed.s.), Design Roots: Local Products and Practices in a Globalised World, Bloomsbury, London, UK.

Micelli, S. (2011), Futuro Artigiano, l'Innovazione nelle Mani degli Italiani [Future Craftsman: Innovation in the Hands of the Italians], Marsilio, Venice, Italy.

Miles, M.B. and Huberman, A.M. (1994), Qualitative Data Analysis: An Expanded Sourcebook, Sage Publications Ltd, Thousand Oaks, CA.

Miller, M. (2017), “The Fraught History of African Textiles”, available at https://www.fastcodesign.com/90108110/the-fraught-history-of-african-textiles (accessed 4 March 2018).

Mirza, S. (2020), Threads of the Indus: The Subtle Forms of Power in Craft Development in Sindh, Pakistan, (PhD thesis) Royal College of Art, London, UK.

Morelli, N. (2015), "Challenges in Designing and Scaling-up Community Services", The Design Journal, Vol. 18, No. 2, pp. 269-290.

Morris, M. and Reed, L. (2008), "A Sectoral Analysis of Skills Gaps and Shortages in the Clothing and Textile Industry in South Africa", available at: http://www.labour.gov.za/DOL/downloads/documents/researchdocuments/Clothing\%20and\%20textile\%20industry DoL Report.pdf (accessed 4 March 2018).

Needham, C. (2008), "Realising the Potential of Co-production: Negotiating Improvements in Public Services", Social Policy and Society, Vol. 7, No. 2, pp. 221-231.

Nonaka, I. (1988), Toward Middle Up-down Management: Accelerating Information Creation. Sloan Management Review, Vol. 29, No. 3, pp. 9-18.

Parker, S. and Parker, S. (2007), Unlocking Innovation. Why Citizens Hold the key to Public Service Reform, Demos, London, UK.

Patrício, L. et al. (2018) "Upframing Service Design and Innovation for Research Impact”. Journal of Service Research, Vol. 21 No. 1, pp. 3-16.

Patrício, L. et al. (2020). Leveraging service design for healthcare transformation: toward peoplecentered, integrated, and technology-enabled healthcare systems. Journal of Service Management, Vol. 31 No. 5, pp. 889-909.

Penin, L., et al. (2016), "Teaching the Next Generation of Transdisciplinary Thinkers and Practitioners of Design-based Public and Social Innovation", Design and Culture, Vol. 7, No. 3, pp. 441-450.

Pink, S. (2015), “Ethnography, Codesign and Emergence: Slow Activism for Sustainable Design”, Global Media Journal: Australian Edition, Vol. 9, No. 2, pp. 16-25. 
Prahalad, C. K. and Hart, S. L. (2002), “The Fortune at the Bottom of the Pyramid”, Strategy \& Business, Vol. 26, pp. 1-14.

Prendiville, A. (2015), “A Design Anthropology of Place in Service Design: A Methodological Reflection”, The Design Journal, Vol. 18, No. 2, pp. 193-208.

Raijmakers, B. et al. (2013), “From Field Stories to Strategic Design”. Touchpoint, Vol. 4, No. 3.

Rhodes, S. (2015), "Reframing Collaboration through the Craft of Ubuntu: Design Students Collaborating with Artisans", Making Futures: Craft and the (Re)turn of the Maker in a PostGlobal Sustainability Aware Society, Vol. 4.

Sangiorgi, D. (2011), “Transformative Services and Transformation Design”, International Journal of Design, Vol. 5, No. 1, pp. 29-40.

Sangiorgi, D. and Junginger, S. (2015), “Emerging Issues in Service Design”, The Design Journal, Vol. 18, No. 2, pp. 165-170.

Santamaria, L. (2017), From Good to Great: Using Cultural Codes to Improve the Design and Value Proposition of Sustainable Product-Service System Innovations, ( $\mathrm{PhD}$ thesis) Loughborough Design School, Loughborough, UK.

Scrase, T. J. (2003), Precarious Production: Globalisation and Artisan Labour in the Third World. Third World Quarterly, Vol. 24, No. 3, pp. 449-461.

Sennet, R. (2008), The Craftsman, Allen Lane, London, UK.

Simonsen, J. and Robertson, T. (2013), Routledge International Handbook of Participatory Design, Routledge, Abingdon, UK.

Smith, R. C. et al. (2016), Design Anthropological Futures, Bloomsbury, London, UK.

Tassinari, V. et al. (2015), "Telling the Stories of Design for Social Innovation: Towards an Ecology of Times", in Cumulus Conference - The Virtual Cycle, 3-7 June 2015, Politecnico di Milano, Milan, Italy.

The Young Foundation (2012), Social Innovation Overview: A Deliverable of the Project: "The Theoretical, Empirical and Policy Foundations for Building Social Innovation in Europe" (TEPSIE), European Commission - 7th Framework Programme, Brussels, Belgium: European Commission, DG Research.

Thomas, N. et al. (2011), Connecting Crafts \& Communities, AHRC, Swindon, UK.

Thorpe, A. et al. (2016), "Public Collaboration Lab", in Proceedings of the 14th Participatory Design Conference, 15-19 August 2016, Aarhus, Denmark, pp. 80-81.

Turnstall, E.D. (2013), Decolonizing Design Innovation: Design Anthropology, Critical Anthropology, and Indigenous Knowledge. In Design Anthropology: Theory and Practice, Bloomsbury, London, pp. 232-250. 
Valsecchi, F. et al. (2016), "Resonances: Listening as a Tool for Trans-cultural Storytelling”, in Lloyd, P. and Bohemia, E. (Ed.s.), Proceedings of DRS2016: Design + Research + Society Future-Focused Thinking, 27-30 June 2016, University of Brighton, UK.

Weick, K. E. (1985), “Cosmos vs. Chaos: Sense and Nonsense in Electronic Contexts”, Organizational Dynamics, Vol. 14, No. 2, pp. 50-64.

Willis, A.M. and Elbana, E. (2017), "Socially Engaged Design: A Critical Discussion with Reference to an Egyptian Village”, Design Philosophy Papers, Vol. 14, No. 1-2, pp. 33-57.

Wilson, J. (2001), Handbook of Textile Design, Woodhead Publishing Ltd, Cambridge, UK.

Yin, R.K. (2004), Case Study Research: Design and Methods, Sage Publications Ltd, London, UK.

Zimmerman, J. et al. (2007), "Research through Design as a Method for Interaction Design Research in HCI", in CHI 'O7 Proceedings of the SIGCHI Conference on Human Factors in Computing Systems, 28 April - 3 May 2007, San Jose, CA. 
design ethnography

1. field notes

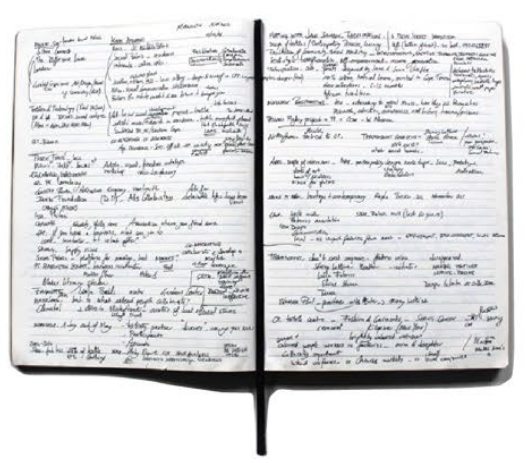

storytelling

2. interview cards
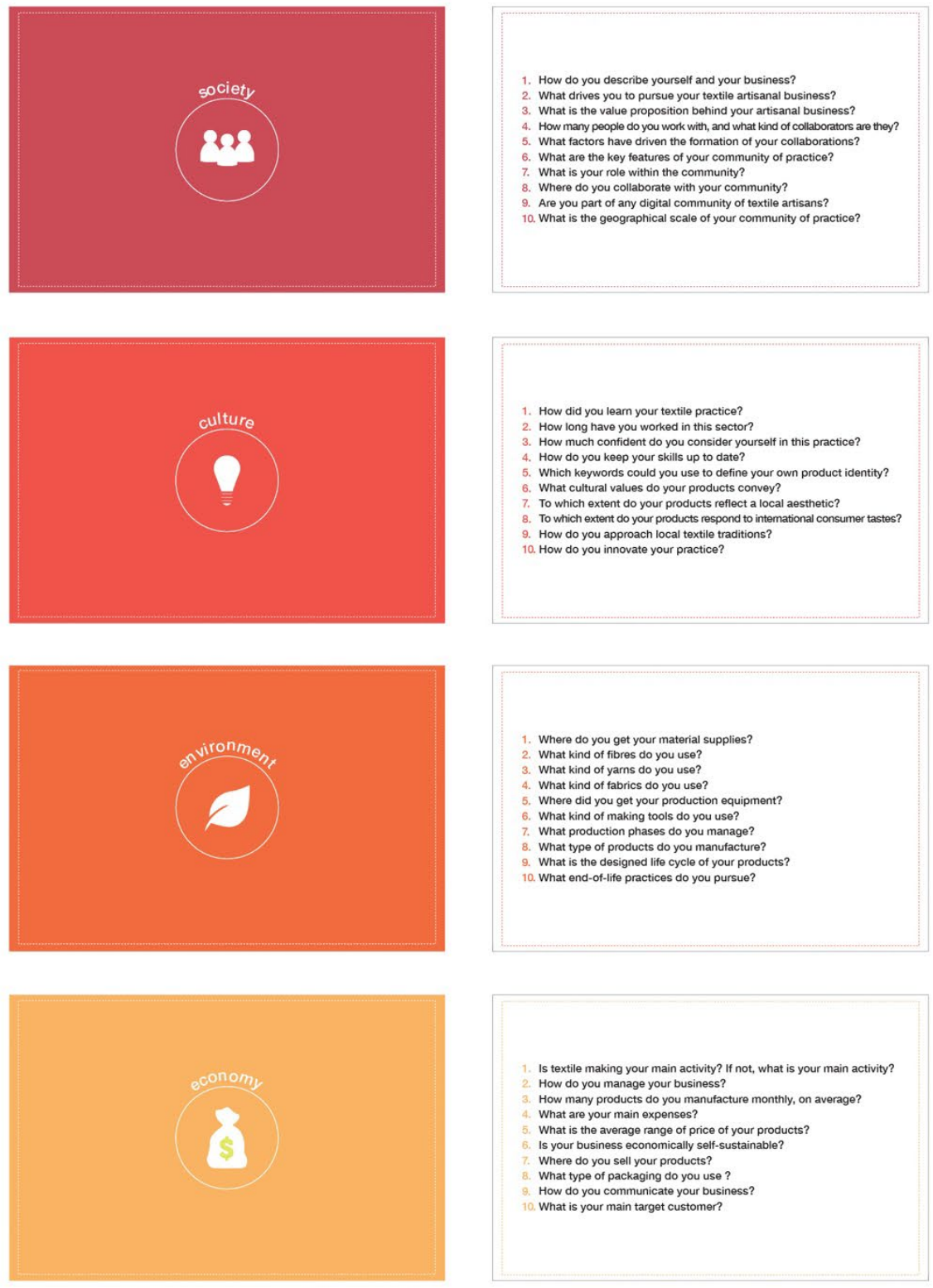

How do you describe yourself and your business?

What drives you to pursue your textile artisanal business?
What is the value proposition behind your artisanal business?

How mary people do you work with, and what kind of collaborators are they?

What factors have driven the formation of your collaborations?

What are the key features of your community of practice?

What is your role within the community?

8. Where do you collaborate with your community?

10. What is the geographical scale of your community of practice?

How did you learn your textile practice?

Howlong have you worked in this sector?

te your own product identity

reflect a local aesthetic

To which extent do your products respond to intemational consumer tastes?

here do you get your material supplies?

What kind a tabics do you use?

What kind of making tools do you use?

Is textile making your main activity? If not, what is your main activity?

e monthly, on average?

What is the average range of

in products?

Where do you sell your products?

What type of packaging do you use?

What is your main target customer? 
storytelling

2. photo-stories
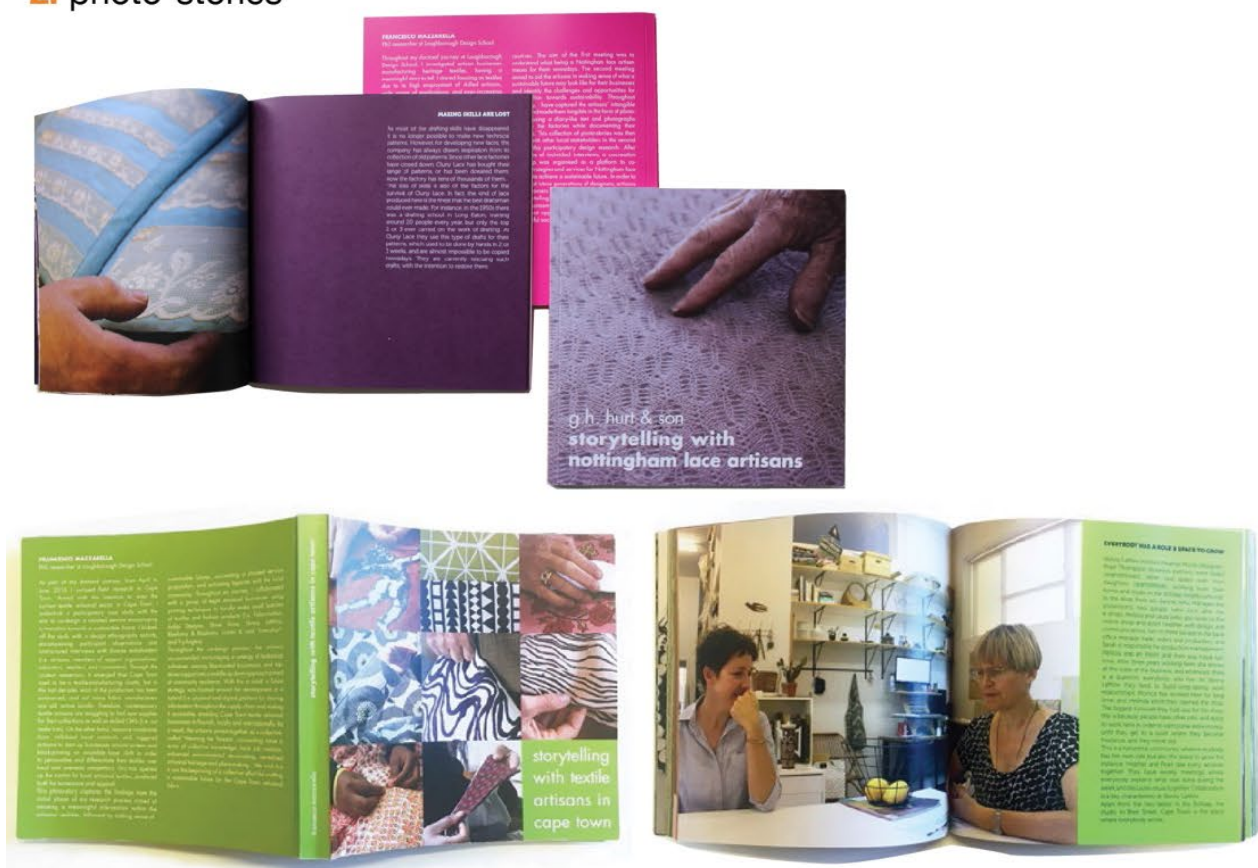

sensemaking

4. framing | 5. what if... $\mid$ 6. ideas generation
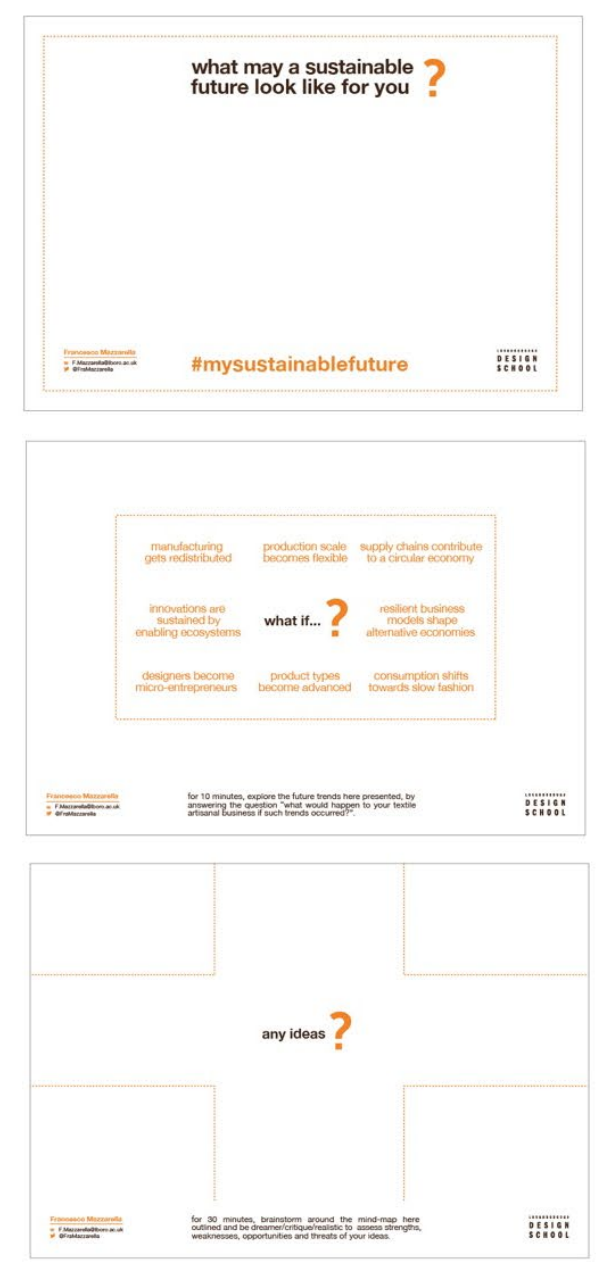
sensemaking

7. future trends cards
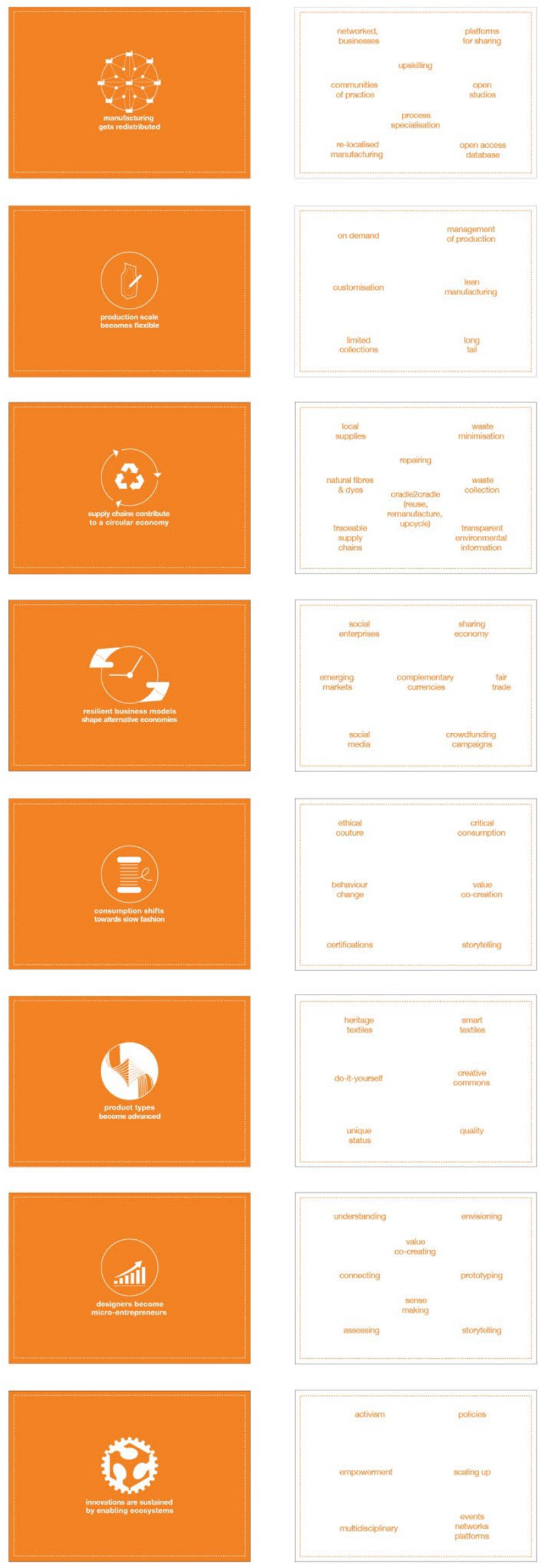
co-creation workshops

8. challenges / opportunities

9. design direction

10. future strategy

11. stakeholders map
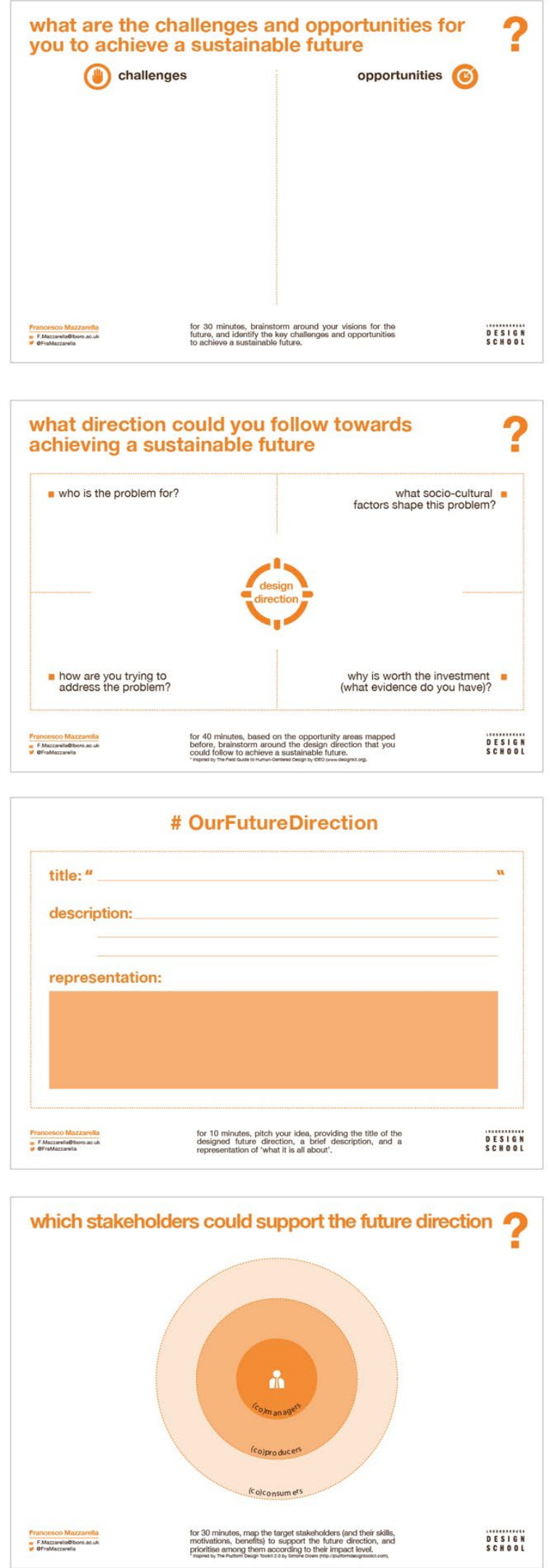
co-creation workshops

12. service storyboard

13. social business model canvas

14. manifesto

what service features could encourage your main $?$ stakeholders towards the future direction

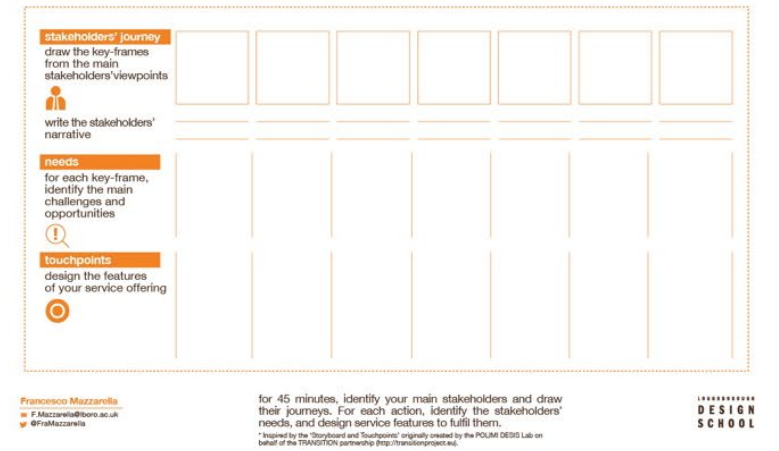

how might your service offering be implemented

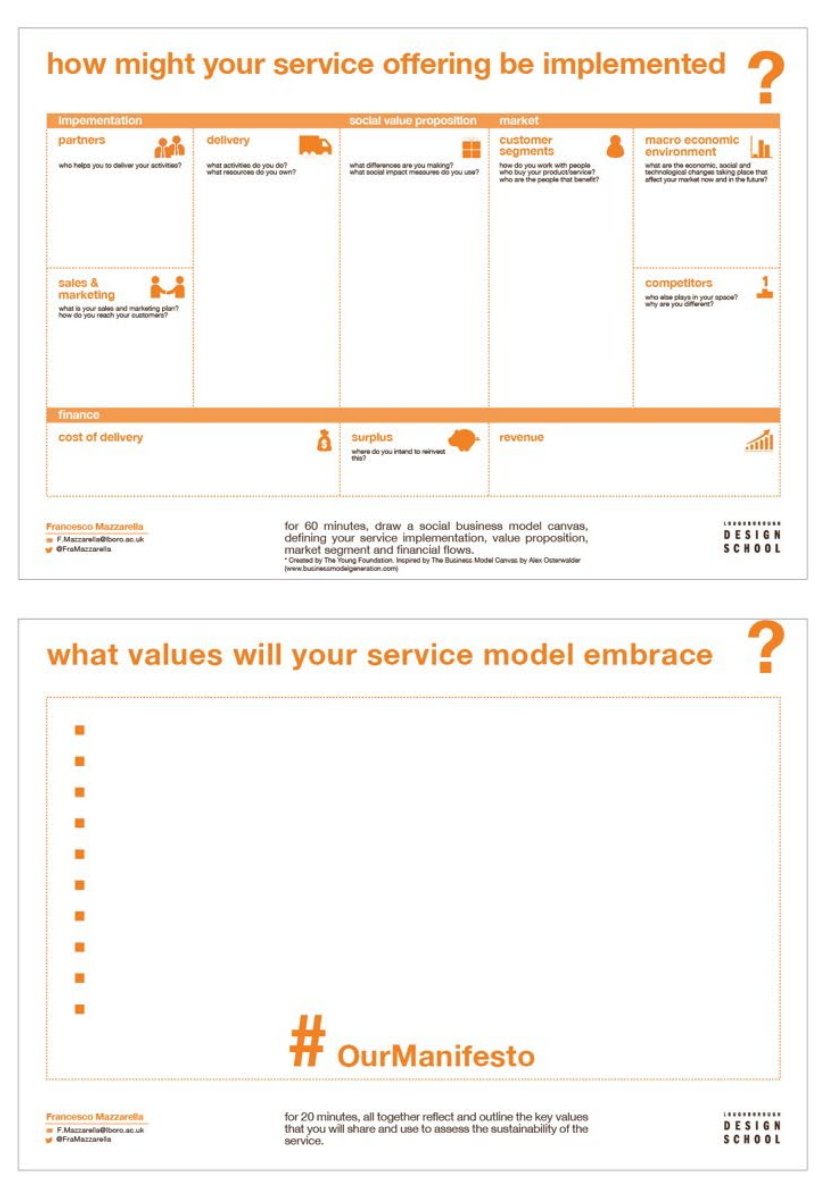

what values will your service model embrace

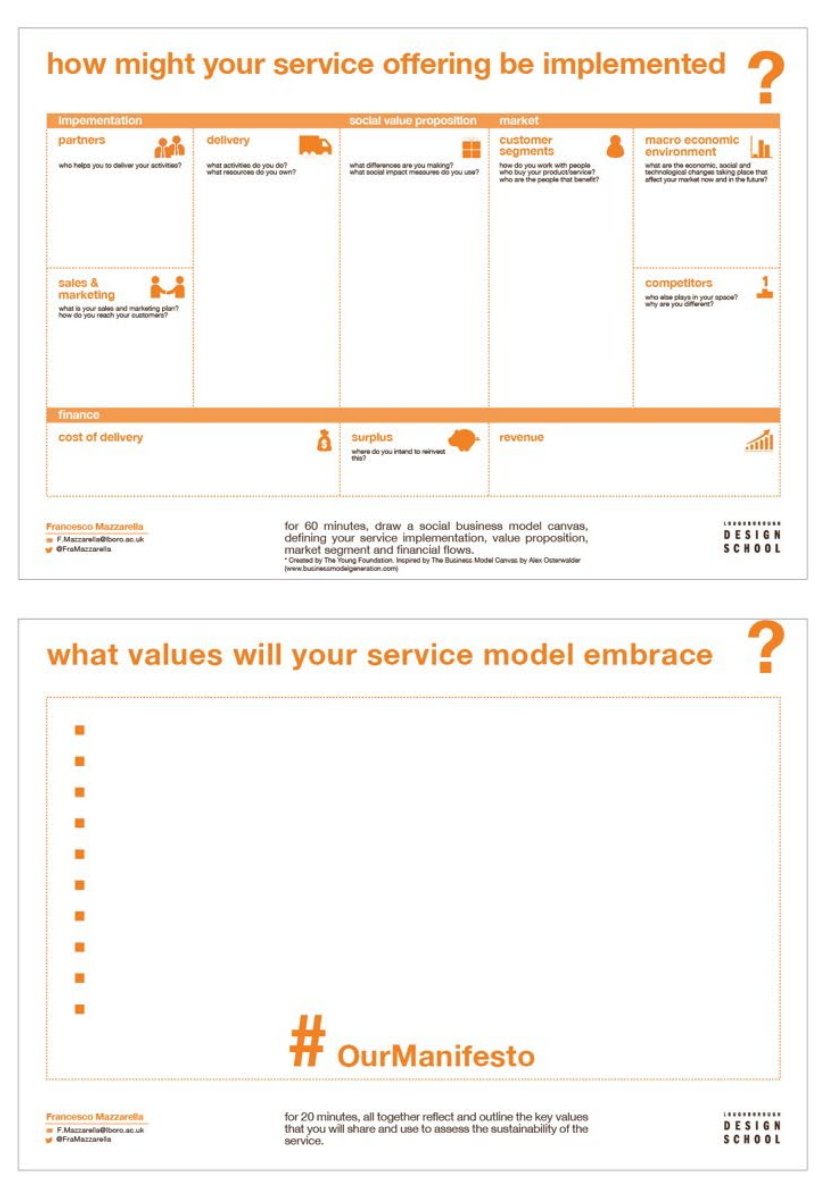

roundtable discussion

15. action plan

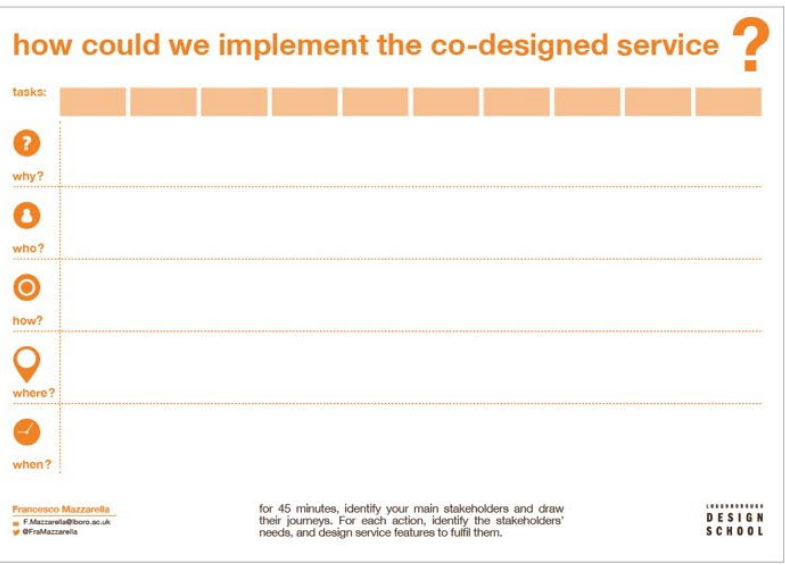

